\title{
LAS OPOSICIONES A LA ORGANISTÍA DE LA CATEDRAL DE SALAMANCA EN EL SIGLO XVII. ESTABILIDAD Y DINÁMICA ${ }^{1}$
}

\author{
COMPETITIVE EXAMS TO BECOME AN ORGANIST IN $17^{\text {th }}$ CENTURY \\ SALAMANCA CATHEDRAL: BETWEEN ORTHODOXY AND INNOVATION
}

\author{
Louis Jambou \\ Université de Paris-Sorbonne \\ louis.jambou9@orange.fr \\ ORCID iD: https://orcid.org/0000-0003-3997-3830
}

\begin{abstract}
Resumen
El presente ensayo estudia el fenómeno social y musical de las oposiciones en un siglo determinado, el XVII, y en un campo preciso, la música de órgano. Predeterminados por los códigos y niveles de saber sociales, sus ejercicios oscilan entre el inmovilismo y la evolución de los conocimientos. El artículo enfoca el fenómeno de las oposiciones en las dos sesiones de la organistía de Salamanca en el siglo XVII, las de 1622 y las de 1699 , y con las propuestas de ca. 1679.
\end{abstract}

\section{Palabras clave mica. \\ España, oposiciones, organista, ejercicios, estabilidad, diná-}

En su artículo sobre las oposiciones a la plaza de maestro de capilla de la catedral de Salamanca de 1789, ganada por Manuel Doyagüe, José Artero distingue tres niveles en los ejer-

1 El título de este ensayo surgió en 2009 como proyecto para el homenaje al profesor Dámaso García Fraile. Pero dicho proyecto no llegó a realizarse. Después de redactado el ensayo, lo edita ahora Аnиаrio Musical, cuya acogida agradecemos sumamente. También agradecemos la amabilidad de Cristina Diego por las sugerencias que nos ha hecho en la redacción del conjunto.

(C) 2018 CSIC. Este es un artículo de acceso abierto distribuido bajo los términos de una licencia de uso y distribución Creative Commons Attribution 4.0 International (CC BY 4.0)

Cómo citar este artículo/Citation: Jambou, L. (2018). Las oposiciones a la organistía de la catedral de Salamanca en el siglo XVII. Estabilidad y dinámica. Anuario Musical, 73: 81-102. doi: http://dx.doi.org/10.3989/redc.2018.73.06

\begin{abstract}
This essay studies the social and musical repercussions of competitive exams in a very specialized field, i.e., organ music. The case study will be the city of Salamanca during the $17^{\text {th }}$ century. This article focuses on the very precise social codes and the highlevel skills pre-required for becoming an organist. Exercises given to the candidates are also analyzed: this allows us to be aware of the evolution undertaken during this century, since they are both conservatives and influenced by newest innovations. This article studies two particular exams which took place in Salamanca in 1622 and 1699 , examining as well the suggestions of subjects given for the 1679 exam.
\end{abstract}

\section{Key words}

Spain, Salamanca, exams, organist, orthodoxy, innovation.

cicios ideados por el maestro de capilla de la sede catedralicia y propuestos a los candidatos ${ }^{2}$ :

- una composición polifónica, en estilo "severo", contrapuntístico.

2 ARTERO (1947): 191-202. Sobre Doyagüe: CASARES (1999): 539-542. Esta oposición sería la base de la novela satírica de Eximeno Don Lazarillo Vizcardi. Véase: EXIMENO (1873). Sobre Artero, ver también: GARBAYO (2004).

ANUARIO MUSICAL, N. ${ }^{\circ} 73$, enero-diciembre 2018, 81-102. ISSN: 0211-3538 doi:10.3989/anuariomusical.2018.73.06 
- una composición de un villancico a 4, con bajón, recitado y aria para solo, de carácter más libre.

- unos ejercicios escolásticos de dirección de conjunto y series de preguntas y respuestas.

Asimismo, en el tribunal se distinguen otros dos niveles: uno "de honor", formado por los canónigos del cabildo, y otro formado por los facultativos, músicos, de la misma catedral o exteriores a ella. Este esquema aplicado a unas oposiciones en un lugar preciso, la catedral de Salamanca, y en una fecha concreta, 1789, se podría ampliar a la mayoría de las catedrales, las colegiatas y, sin duda, otras instituciones del territorio de la península, e incluso a otros países, desde principios del siglo XVI hasta el XIX e incluso el XX, sin caer forzosamente en las críticas caricaturescas descritas en el Don Lazarillo Vizcardi ya anunciadas por Pietro Cerone en $1613^{3}$. Podría decirse que, generalizando y pese a los cambios sociológicos, religiosos o políticos, sus esquemas básicos, tanto administrativos como técnicos, musicales en este caso, llegan a nuestros días. Esta generalización encierra la tentación de la rigidez y del inmovilismo, entre novedad y academismo, cuando uno no puede dejar de pensar que durante un lapso de tiempo tan largo no puede haber sino variantes y modificaciones dentro de unas mismas normas canónicas que de novedosas en su inicio se hacen académicas a lo largo del tiempo [Como caso paradigmático en los siglos XIX-XX: LU \& DRATWICKI (2011) $]^{4}$. Este doble nivel, administrativo y técnico, ignora sin embargo otro nivel que forma el sustrato de la formación musical del organista, que es la funcionalidad del cargo, la liturgia. Su base y realidad es por una parte el canto monódico, el del canto llano, ya llamado y futuro "canto gregoriano", con su hipotético acompañamiento, y por otra el canto polifónico, "canto de órgano", con su propio acompañamiento. La valoración de este nivel queda fuera de este ensayo por falta de material sonoro, aunque por las suge-

3 CERONE (1613): I, cap. 53, 150-151. Cerone no critica ni nombra las oposiciones, pero sí critica alguna de sus consecuencias, que han llegado hasta nuestros días en los empleos de la función pública: “...si la gente ordinaria [en España] deprende algo de música, imaginando voy que no deprenda con el mesmo fin que los italianos, mas solo por alcançar aquella plaça de 300 y aquella de 500 ducados. Quiero dezir que si no huuiera en España las buenas plaças y las grandes prouisiones que ay, que tampoco entre esta gente se hallaran (al margen: "ay plaças y prouisiones muy ricas en España para Cantores y Musicos" [p.151]), tantos Musicos, ni tanto numero de Cantores como se hallan; pues vemos cada día, que alcançado que tiene el Cantor, el Organista y el Maestro de Capilla una plaça que sea buena, no tiene gana para estudiar mas, ò por dezir mejor, no quiere procurar saber mas de lo que sabe...". De mucho interés sería que un trabajo sintético sobre este modo de acceso a las plazas musicales se realizara en España. Dada la singularidad de España, que sería casi única, según Cerone (pocos ejemplos hay en efecto en su entorno) en la práctica de las oposiciones sería un primer y nuevo paso para poder compararlo con las mismas u otras prácticas europeas para definir estilos o escuelas.

4 Los dos polos de este premio prestigioso, guía de la formación y creación musical francesa durante dos siglos, son el estilo fugado y la cantata. rencias de los temarios no se pueda ignorar esta faceta práctica exigida de los organistas opositores.

En sus manos, Artero [GARBAYO (1999)] tenía el expediente entero de las oposiciones a plazas de músicos de su catedral - fue maestro de capilla en la misma catedral salmantina - y propone un plan ambicioso y comparativo de estudio de todas las composiciones de opositores y jueces. No llegó, y no se ha llegado, a cumplir tanto deseo, pero quiso el autor llamar la atención sobre el interés de tales expedientes, legajos o "papeles", cuando existen, no sólo con los dictámenes de los jueces sino con las realizaciones prácticas de los propios opositores. Yace en ellos una mina de información sobre las prácticas musicales de cada época, en un doble estrato:

- el de los ejercicios de los opositores, que son reveladores del cumplimiento o no de las normas exigidas.

- el del pensamiento musical a través de los juicios emitidos por los miembros músicos de los tribunales.

Estos documentos forman pues el canon o modelo de la práctica y de la teoría musical de una época. Por otra parte, en la diacronía, permiten valorar en el tiempo las variantes en los ejercicios o, mejor dicho, su adaptación a la evolución del mismo lenguaje de la música y de las condiciones de su ejecución. Así, en los ejercicios propuestos en Salamanca en 1789, es de interés valorar la diferencia entre los dos niveles de composiciones exigidas al opositor: el de un motete y el de un villancico. Pero a la vez, el decir esto plantea otra pregunta cuya declaración generaría una investigación en torno a la aparición del villancico en las oposiciones a plazas de maestro de capilla catedralicios. No es extraño que este género parezca introducirse como ejercicio exigente en las oposiciones a partir de finales del XVI o principios del XVII (en 1587 y 1593 en, Zaragoza $^{6}$, en 1604 en Toledo ${ }^{7}$, en 1606 en Ávila ${ }^{8}$ ) cuando precisamente se aprecia en la música un cambio sustancial de orientaciones estilísticas. Consecuentemente uno no puede dejar de unir el motete al estilo antiguo y el villancico al nuevo estilo de finales del XVI y principios del XVII.

$5 \mathrm{El}$ autor de este artículo realza el aspecto pionero del ensayo que comentamos.

6 CALAHORRA (1978): 349, 352, 355, 357-358, 360.

7 REYNAUD (1996): 135. VILLANUEVA (2002): 922, lo da por sentado en los ejercicios a magisterio de capilla a mediados del siglo XVII, estableciendo asi un doble nivel de composición musical en la iglesia.

8 Archivo de la Catedral de Ávila $(\boldsymbol{E}-A c)$, legajo 3/ na 124 , Capellanías Raciones y Canonicatos, Año de 1605. Contralto y Organista. El 02.01.1606 ..."confirieron y determinaron [los Capitulares] [...] [que] el maestro de capilla y los musicos con el organo portatil de la sala aquí en el Cabildo examinen al d[ic]ho Juan Alvarez en la forma ordinaria preguntandole el Maestro lo que le pareciere y se le de un villancico o motete qual parezca al maestro de capilla y le trayga compuesto pra mañana y le taña ante sus $m[e] r c e[d] e s$ en presencia del maestro de capilla y los musicos" $[\ldots]$ El "villancico" no figura en las oposiciones a organistía de 1604 (legajo3/n¹07) en que se concede la plaza a Francisco Díaz, de la diócesis de Portugalete y organista de la catedral de Plasencia, el cual ha tañido "el organo los dias q[ue] fueren necess". 
Este ensayo no llegará a resolver todos estos problemas, que merecen un estudio largo y complejo. Tan solo pretende volver a abrir algunos expedientes del legajo consultado por José Artero y editar a continuación su contenido, observando desde ahora algunos puntos dignos de atención.

\section{A- OPOSICIONES DE 1622, 1699 Y 1679C (MEMORIA DE JUAN DE TORRES ROCHA).}

\section{A1-Esquema de las oposiciones del siglo XVII}

Son dos los expedientes de oposiciones a plazas de organistas que se conservan del siglo XVII ${ }^{9}$ : uno de 1622 y el segundo de 1699. En 1622, se provee a la plaza dejada vacante por la muerte de Tomé Hernández, que también tenía la cátedra de música de la Universidad ${ }^{10}$. El segundo expediente consta además de una "memoria" sin fecha que se debería a Juan de Torres Rocha ${ }^{11}$, el maestro de la capilla salmantina entre 1654 y $1679^{12}$ : la memoria sería pues, en principio, anterior a la fecha de 1679. La oposición se organiza después del fallecimiento, en 1699, de Francisco Sanz de Texada ${ }^{13}$ y los edictos se envían a 33 catedrales ${ }^{14}$. La memoria de Torres Rocha marca una etapa intermedia, que suponemos ser las oposiciones a organistía de la catedral de Salamanca, que podría haber sido el plan de ejercicios que ganó Antonio Brocarte en $1676^{15}$. Aparecen pues durante el siglo XVII tres programas en la misma catedral durante los cuales el instrumento pasa del teclado partido, que ya tiene a principios de siglo, al órgano de finales de siglo con su trompetería horizontal y su sistema expresivo de ecos, que en Salamanca no parece haberse adoptado hasta los años 1700-1702.

9 Archivo de la catedral de Salamanca (E-SA): cajón 48, leg. 2, $\mathrm{n}^{\circ} 1 \mathrm{y} \mathrm{n}^{\circ} 20$

10 E-SA, Actas capitulares 1616-1630, fol. 30r -01.03.1622- y 61r. -04.03.1622-. Los edictos se envían a 11 catedrales; $64 \mathrm{r}, 73 \mathrm{v}, 90 \mathrm{v}$. El 27.05.1622 Manuel Nieto, elegido, escribe desde Santiago para decir su gran necesidad, con sus obligaciones y una casa con 5 hijos (fol. $115 \mathrm{v})$ y el mismo día se vaca la plaza proveyendose, con 41 votos, en Hemando de Herrera, organista de la catedral de Palencia (Vease figura 1). Sobre Fernando de Herrera: CRUZ (2013).

11 EZQUERRO (2002a) (artículo muy documentado) sobre los diferentes y posibles Torres [Rocha?].

12 Por los mismos años, en 1669, Torres Rocha se opone a la cátedra de música de la Universidad salmantina frente a Gaspar Sanz, oposición de donde se retira: GARCÍA FRAILE (1990). Volverá a ocupar la cátedra de la Universidad entre 1675 y 1679.

13 Fue organista de la catedral salmantina entre el 17.09.1686, en que toma posesión y el 19.09.1699, fecha en que muere: PRECIADO (1976): 45, 49.

$14 \boldsymbol{E}$-SA: cajón 48 , leg. 3 , n 20 : se despachan el 30 de septiembre. El término se cierra el 11.11.1699. Además de los dos candidatos (figura 2) también se reciben cartas de Jacinto Navarro organista de la catedral de Jaén (una el 14.10.1699 y una segunda, en la cual renuncia a oponerse, el 04.11.1699). El 09.10.1699 se recibe una carta de Simón Martinez de Ocho, maestro de capilla de Soria, quien recomienda a Jacinto del Río, organista de la catedral de Coria, que tambien toca el arpa.

$15 \boldsymbol{E}$-SA: cajon 48, leg. $2 \mathrm{n}^{\circ}$ 1l: el expediente de la elección de Brocarte no consta en los ejercicios. Comprende los edictos, "por muerte de Sebastián Domínguez", y la lista de los destinatarios (24).
A1a-Esquema de las oposiciones de los días 06 y 07.05.1622 (Apéndice I, $\mathbf{a}^{16}$ )

- En un realejo: ejercicios [práctico-teóricos]

- Ejecución de motetes [según elección del maestro de capilla]

- Composición de motetes [y su estudio].

- Ejecución de los motetes por los opositores

A1b-Esquema de la memoria supuesta de Juan Torres Rocha [en o antes de 1679] (intercalada en el Apéndice II, en c)

- En un realejo partido.

- Ejercicios de contrapunto sobre bajo y tiple en canto llano y canto de órgano, con compás y tiempo variados.

- Ejercicio escrito de un bajo dado.

- Ejercicios de acompañamiento de voz e instrumentos varios.

- Ejercicios de trasportación sobre canto llano y reconocimiento del modo.

- Ejercicios de imitación de voz o instrumento en canto llano o canto de órgano.

- Ejercicios práctico/teóricos sobre los modos: Kirie, verso de Magnificat.

- Acompañamiento e imitación de un "cuatro".

- Acompañamiento e imitación de una tonada.

- Acompañamiento natural o accidental (trasportado).

- Improvisación de un partido de dos tiples sobre un paso.

- Improvisación de un partido de dos bajos sobre el mismo u otro paso.

- Entonación de un himno.

A1c-Esquema de las oposiciones de los días 11-17.11.1699 (Apéndice II, b, d, e, f, y con la evaluación y el resultado de la votación-provisión en g)

- En un realejo partido.

- Ejercicios de contrapunto sobre bajo y tiple en Cantollano, con compás y tiempos variados.

- Ejercico escrito y práctico de un bajo dado: composición, ejecución al realejo y por los cantores.

- Ejercicios variados de contrapunto (bajo, tiple, contralto) sobre canto de órgano, con compás y tiempos variados.

- Ejercico escrito y práctico a 4 sobre un paso a compasillo y otro a proporcioncilla.

- Ejercicios teóricoprácticos de acompañamiento e improvisación sobre los modos y su trasporte.

16 En los apéndices las letras a) b) vienen en negritas; los números entre corchetes [...] vienen en versalitas en IIb, II c y IIe y ponen en relación el proyecto de 1679 con los ejercicios realizados en la oposición de 1699; en g) separan los distintos momentos de la última sesión de la elección de Pedro de Sa[n]martín y [de] La Calle al cargo de organista. Se añaden al original en la transcripción. En principio facilitan el "va y viene" de la lectura entre el análisis y los apéndices. 
- Acompañamiento de un villancico cantado por los cantores.

- Ejecución o improvisación libre.

\section{B- ASPECTOS FORMALES Y GENERALES DE LAS OPOSICIONES DE 1622 Y 1699}

Los dos grupos de examinadores del tribunal definidos por Artero ("de honor" - formado por los miembros del cabildo- y "técnico" - incorporado por facultativos músicos-) están constituidos en principio por miembros que tienen voz y voto en el momento del nombramiento al cargo sometido a oposiciones. Este reparto sufre excepciones, teniendo en cuenta que al final solo tienen voz y voto los miembros titulares del Cabildo. Así, en 1622 este tribunal técnico está formado por miembros todos ellos músicos externos al Cabildo, integrados o no a la plantilla de la Catedral. Dirigido por el maestro de capilla de la sede catedralicia Sebastián de Vivanco, está también integrado por racioneros cantores de la catedral y por miembros exteriores a la plantilla de la catedral que son religiosos organistas de los monasterios de San Agusín, San Francisco y Santo Domingo, que no se nombran en las actas capitulares ni en el informe (Figura 1 y Apéndice I a). Está claro que al final todos estos miembros "informan" al Cabildo de las cualidades y bondades de los oposositores en una sesión que precede a la votación de los canónigos (Apéndice I b). En 1622 se ha de resaltar el papel de cinco de estos racioneros músicos (Moreno, Floriano, Valentin, Ramírez, Castro) cuya formación musical se desconoce (¿licenciados en artes de alguna Universidad? o ¿prácticos de la voz o de algún instrumento con conocimientos teóricos y prácticos?).

Asimimo, en 1699 son los "racioneros titulares inteligentes en música" (Diego Cantero de Victoria y Pedro de Pineda), los "racioneros músicos" (los cantores Marcos Castañón y Santiago de Ribera, que se remiten al parecer del "Cabildo"), y otros cantores (Francisco García, Domingo García, Nicolás de Hasundeaga, Garpar de Ynsaluarte, Miguel de Castillanos, Montenegro) que informan al Cabildo que Pedro de $\mathrm{Sa}$ [n]martín y [de] La Calle aventaja a Matheo de Pocurull (Apéndice II, g[2]).

Todos ellos forman un grupo numeroso en las catedrales y totalmente desconocido por la historia de la música y son músicos asesores del Cabildo. Es, sin duda, el caso de Domingo García (apéndice II e, e[9] y e[15], e[16], Apéndice III (a) o, en menor medida, el de Pedro de Pineda (apéndice IIc, IIe). Como apuntamos más abajo, por prudencia del maestro de capilla Tomás de Micieces y del Cabildo, Domingo García parece desempeñar un papel técnico sustitutivo en las sesiones de 1699, notable en sus conocimientos.

Antes de pasar al examen técnico de la oposición de 1699 conviene observar con detenimiento el protocolo en su conjunto, desde la vacante de la plaza y los consecuentes edictos, hasta la misma oposición y su conclusión, con la proclama de los resultados y el cálculo de los gastos (Véase Apéndice II, de a hasta h). Téngase en cuenta que el Cabildo, presente en las sesiones, representa, según la expresión utilizada por Artero, el "tribunal de honor", cuyos miembros tienen voz y voto: son 44 en 1622 y 43 en la oposición de 1699. Por su parte, el "tribunal" de los asesosores musicales, en su definición propia, controla las sesiones téoricas y prácticas: son 5 en 1622 y 10 en 1699. Pero éstos, salvo excepciones, no participan en el voto final. En 1622 votan los 44 miembros "de honor" de los cuales 36 votan por Manuel Nieto. En 1699 en Salamanca, la votación final se decide entre los 43 miembros, del tribunal de honor, siendo elegido Pedro de $\mathrm{Sa}$ [n]martín y [de] La Calle por 29 votos contra 14 para su coopositor, Mateo Pocurull (figura 1 y 2 y apéndice II, g4).

Son varias las observaciones generales que vamos a resaltar: el formalismo de las normas va unido a una seriedad general. El formalismo se da en este caso, sin duda alguna, en la minuciosidad del secretario de las sesiones (sin duda el secretario del Cabildo del mismo año) en ir anotando los aspectos más nimios y sucesivos de su desarrollo. El informe consta de unos 21 folios manuscritos que se transcriben en los apéndices en su totalidad. Incluso este formalismo, que pasa por una constante seriedad, llega a una sobriedad retorcida en el manejo maniático - para no olvidarse de lo más nimio - del idioma.

Además, a este aspecto formal no le falta otro, ético esta vez, al apuntar la posible pérdida de tiempo de los opositores al faltar a las obligaciones de su cargo oficial en la catedral de su procedencia, o la separación física de los opositores para que uno no asista a los ejercicios de su contrincante (II, a, e: dos veces, f. g...), que lleva a observar su minuciosidad para evitar cualquier fraude (II, a y e), la prudencia de los jueces frente a la autoría del plan para oposiciones a organistía de Torres Rocha de ca 1679, que se duda sea una copia o su original (II,e). Finalmente éste se atribuye al maestro de capilla Tomás de Micieces, miembro del tribunal que, dice el informe, "cassi lo confessó". Precisamente el papel del maestro de capilla, cuñado de uno de los opositores (Pedro de Samartín) en participar o no en todas las sesiones (II, b , c y e), y su ausencia en la votación final (II, g4), deja parecer que tiene una actitud harto ambigua, interesada sin duda en la elección de su cuñado.

\section{C- ASPECTOS TÉCNICOS DE LAS OPOSICIONES DEL SIGLO XVII}

Las diferencias técnicas y materiales entre las distintas oposiciones son obvias. En 1622 parece que hay una lógica interna en el desarrollo de los ejercicios, pero éstos no se transcriben o, por lo menos, no se conservan, y la duración de los ejercicios, de dos jornadas, queda truncada por motivos circunstanciales que no se aclaran. El plan de los ejercicios de 1699, que duran del 11 al 17 de noviembre incluidas todas las sesiones, sería muy parecido al que dejaría el maestro de capilla Torres Rocha; el de 1699 se transcribe (Apéndice II, c) en su totalidad. El desarrollo de las sesiones lo respeta en su espíritu, aunque merece destacar que faltan todos los detalles en el informe por lo menos; pero poco se puede dudar de su veracidad (ejercicios II, c [2 a 15], e [2 a 16]). Cierra la oposición la votación del Cabildo y proclama de sus resultados (Apéndice II, e[16], f, g[4]). 
Los ejercicios efectuados son en principio adecuaciones a la realidad de cada época y lo que mejor refleja la práctica musical de ese momento. Pero a la vez no traducen toda la realidad musical de lo que se enuncia entre los miembros del tribunal o del Cabildo, de la lengua musical hablada por ellos. Comparemos por ejemplo una fórmula que aparece en los informes del secretario de ambas oposiciones de 1622 y 1699. En 1622, el amanuense escribe que "el Cavildo mandó y ordenó fuesen examinados [los opositores] y q[ue] cada uno hiçiese sus exercicios y para el d[ic]ho effecto fuesen entrando por sus antigüedades en el d[ic]ho Cavildo y tocasen los motetes q[ue] por el d[ic] ho señor maestro de capilla se les ordenase" (Apéndice I, a). Asimismo, en 1699, antes de que empiecen los ejercicios, el secretario anuncia, los días 11 y 12 de noviembre, que la serie de ejercicios va a empezar, escribiendo que "bayan entrando assi los $\mathrm{d}[\mathrm{ic}]$ hos dos oppositores, como los demás que vinieren a hacer sus ejercicios y ser examinados, y tocar los motetes que les fueren señalados" (día 11.11.1699] (Apéndice II, a) y "fuessen entrando por sus antigüedades, entrando el primero el más moderno [= joven], a haçer sus ejercicios y ser examinados, $\mathrm{y}$ tocar los motetes que les fuessen señalados, y por el $\mathrm{s}^{\mathrm{r}} \mathrm{R}^{\circ} \mathrm{D}^{\mathrm{n}}$ thomas de Miziezes Maestro de Cappilla de dha Santa Yglessia, les fuesse ordenado" [día 12.11.1699] (Apéndice II, b).

Esta fórmula, "tocar los motetes", reiterada e incorporada entre otras fórmulas asimismo reiteradas, no puede reflejar la misma realidad musical en una y otra circunstancia: en 1622 puede que refleje aún, y sin duda es así, uno de los ejercicios del estudiante instrumentista pero, a finales de siglo, en 1699, ya no tiene significado este ejercicio musical o entra en el ciclo de su formación. Es evidente que "tocar los motetes que les fueren señalados" que se repite y escribe una y otra vez es, en 1699, ritualizada, totalmente rutinaria y se copia sin modificación alguna. Es una norma cosificada que, además, desaparece, aunque no del todo, lo que dejan claro los ejercicios tanto de uno como de otro, tales como aparecen en los días siguientes (Apéndice III, Ejercicios de 1699).

Ahora bien, uno puede vacilar en la interpretación de fórmulas repetitivas de las oposiciones de 1622 y de 1699 , entre el mero estudio y ejecución de obras motetísticas y la composición de las mismas seguida de su ejecución al realejo, lo que haría de este ejercicio uno parecido a lo que se le exige al opositor para conseguir una plaza de maestro de capilla.

En 1622, entre las fórmulas que siguen no puede haber mucha duda: los opositores han de tocar un motete o su adaptación; en todo caso es una obra que no se define pero que está conforme al estilo antiguo, motetístico:

\footnotetext{
- "tocassen los motetes q[ue] por el d[ic]ho señor maestro de Capilla [Vivanco] se les ordenasse", - "hiço los ejercicios y tocó los motetes",

- "hiço los mismos ejerçicios y tocó los mismos motetes",

- "traeran sus motetes estudiados..." (Apéndice I, a) ...

- "tocar en el rrealejo que en él estaban los motetes que por el señor maestro de capilla de esta santa yglesia de luego los di[ch]os motetes se les avían dado",

- "...cada uno por su antiguedad entraron y tocaron en el $\mathrm{d}[\mathrm{ic}]$ ho rrealejo los $\mathrm{d}[\mathrm{ic}]$ hos motetes..." (Apéndice I, b).
}

El 11.11.1699 la cita de este tipo que contiene el vocablo "motete" aparece en el cabildo previo al comienzo de los ejercicios. Se repite, es verdad, el día siguiente 12 de noviembre, pero antes de comenzar los ejercicios.

- “...baya entrando assí los di[ch]os dos oppositores, como los demás que vinieren à açer sus ejerçicios y ser examinados, y tocar los motetes que les fueren señalados..." (Apéndice II, a).

- "... [los opositores] fuessen entrando por sus antiguedades [...] a haçer sus ejerçicios y ser examinados, y tocar los motetes que les fuessen señalados..." (Apéndice II, b).

Sin embargo el vocablo "motete" no vuelve a inscribirse después de su enunciado, en el cuerpo del informe. Así, en 1622, a los opositores se les presenta una obra de polifonía vocal, y éstos han de "ponerla en el monacordio". Su papel se limita aquí a transcribir una obra vocal para su instrumento, estudiarla y tocarla en el realejo. La amplitud semántica de la expresión "hacer sus ejercicios" no despeja la duda ante su contenido, pero se puede suponer que, en el ejemplo de 1622, éste no podía pasar de su glosa o de la imitación de uno de sus intentos, es decir de ejercicios de improvisación. En 1699 los racioneros músicos de la catedral (Apéndice II, g3) se refieren a las cualidades de Samartín, bondades que remiten ya a su destreza y "gusto" interpretativo, de forma que excede a su contrincante "en Çiencia, Manos y idea", con lo cual ha sabido ejecutar "los tañidos al órgano con más primor y destreça y tener en ellos mejor gusto", lo mismo que en "el órgano a las horas del Coro", es decir en las horas canónicas (lo que no aparece en el plan de preguntas).

Las oposiciones a organista de 1622, en Salamanca, aparecen así como meros ejercicios de interpretación de una música vocal que está al servicio del culto religioso. El organista es, pues acompañante de la voz, aunque se aparte de ello. Por otra parte, estos ejercicios revelan una única faceta de la formación del organista que pertenece a la primera mitad del siglo XVI: el estudio del estilo motetístico y, a partir de este modelo, su repetición. Cualquier oposición, de todo tipo, tiene un objetivo: hacer perenne un modelo anterior, preexistente. Pero en este caso esta rigidez se aplica indiferentemente, o de igual modo, a la voz y al instrumento. Sin embargo, bien sabemos que la realidad, en los años 1620, es otra y que los compositores organistas del momento, los Peraza, Correa de Arauxo o Aguilera de Heredia por ejemplo, ya revelan otro mundo organístico que se va alejando de este modelo. Queda claro que la oposición salmantina de 1622 responde a un deseo de regular e inmovilizar una realidad musical que es móvil y cambiante. Hacerla atemporal, aplicándose al realejo que no sabemos si responde, o no, a las obras compuestas por los citados organistas.

En las oposiciones de 1699 sabemos, por los ejercicios libres de interpretación, que este realejo previsto en la memoria de Torres Rocha/Micieces que sirve para las oposiciones de 1699 es ya órgano de teclado partido, para bajo o para tiple ("a medias es verdad”: Apéndice II, c[116]. Además de las obras exigidas, para dos bajos o dos tiples (en ca.1679 y en 1699: apéndice II, 2c y II e), son ejercicios de alto vuelo que pertene- 
cen plenamente al siglo XVII. Precisamente el plan ideado por el maestro salmantino es exigente y requiere un grado de conocimientos teóricos y prácticos elevado. Sin embargo, ninguno, aparte de una realización que se ha de hacer "sobre el papel", supone unas realizaciones escritas, ya que todas ellas se han de tocar en el instrumento realejo. En la oposición de 1699, calco y duplicado de la memoria de ca.1679, se prefiere pues la ejecución e interpretación "de improviso", la improvisación, y no el ejercicio de las " 24 horas" que es ya característico de la oposición a maestro de capilla y lo es también para la de organista.

Por los distintos puntos y sesiones de trabajo (Apéndice II c) se nota, en 1699, que todos los campos de la teoría entran en las realizaciones de los opositores: contrapunto sobre canto llano, es decir simple, contrapunto sobre canto de organo, y de "concierto" con los intentos, pasos o temas en las distintas voces. Asimismo se proponen ejercicios en compases y ritmos varios, con tiempos distintos, acompañamientos del canto del Kyrie de la misa o de un villancico, trasportaciones improvisadas de obras en el instrumento, improvisaciones sobre temas de las obras consideradas e, incluso, ejercicios prácticos de acompañamientos de canto polifónico en el coro. Finalmente la ejecución de obras de libre elección hace de la obligación de tocar obras para dos tiples o dos bajos del plan de Torres Rocha/ Micieces (Apéndice II, c [16]) una sesión lucida y dificultosa sin duda, pero más leve y grata para los opositores.

En todo caso, se debe resaltar la solidez, el plato fuerte, de este plan de ejercicios de la segunda mitad del siglo XVII y que se aplica en gran parte en 1699. También conviene insistir en que su contenido, aunque no se busquen detalles, es el que abarcan los estudios musicales de este siglo. De forma que parece que hay conformidad y coincidencia entre sus exigencias y las realizaciones de los opositores. Sin embargo se realza que el papel del organista es el de acompañante del oficio litúrgico, en el campo del canto polifónico y no del coro, canto "gregoriano". Si no hay ruptura, sí parece claro que, entre 1622 y 1699, el lenguaje del instrumento se ha adaptado a la teoría de su época. No hay ruptura por cierto pero sí evolución, que resalta que el instrumento se ha liberado de la escritura vocal en parte de sus ejercicios (Apéndice II, e [16]).

Aunque sea brevemente queda por calibrar otro punto: el de los mismos ejercicios de los opositores, que sólo se pueden apreciar para 1699, entre los dos opositores: por un lado Samartín que procede de la catedral de Astorga y por otro Pocorull, que procede de la de Ciudad Rodrigo. Ambos efectúan los cortos ejercicios (se transcriben en Apéndice III, Ejercicio 2, 3 y 3') en la misma sala capitular, con tiempo limitado y bajo la tensión y presión que se puede suponer (lo que se nota en la prisa en concluir algunos ejercicios) en presencia de los miembros del cabildo, del tribunal, y del público que quiera asistir.

Sale elegido $\mathrm{Sa}$ [n]martín y [de] Lacalle. Aunque no podemos tener a la vista, y menos aún oír la totalidad de los ejercicios, sobresale este organista que lleva la plaza frente a su competidor con 28 votos a su favor, contra 14 a favor de Pocurull.

Los ejercicios teórico-prácticos tocados en el realejo no dejan huella escrita alguna de su realización. El enunciado de su desarrollo permite afirmar que la parte práctica, ejecutada o improvisada, ocupa un largo espacio de los ejercicios que los opositores tocan en el realejo (II, c 7, 9, 10, 11, 12, 14), entre los cuales destacan su capacidad en el "tañer y cantar" de su oficio. Por otra parte, interviene la capilla y el realejo para acompañar el villancico. Los opositores participan igualemente en algunas horas del coro (Apéndice II, g3). Todo ello permite al opositor, como dijimos, lucir sus talentos en el acompañamiento del canto polifónico así como del canto monódico (Kyrie).

Además de esta serie de ejercicios teórico-prácticos, ambos opositores han de someterse también a una doble serie de ejercicios escritos distintos. Uno y otro opositor escriben una primera serie. (Apéndice III, Ejercicios 1 y 1') de manera autónoma: es un ejercicio escolástico dividido en dos partes; la primera se basa en un bajo dado a modo de Canto llano o cantus firmus; la segunda se basa, como cantus firmus, en el hexacordo. En principio responde al ejercicio 1 del plan de Torres de 1679, "contrapuntos sobre bajo en Cantollano, a compasillo, Compás maior, seisquialtera, ternario maior y menor, semibrebes al Alçar y Mínimas semicopadas [sic]" que (Apéndice II b, y c [1]) se ha reducido a dos aspectos haciendo además los semibreves sincopados sobre las notas del hexacordo en cantus firmus. En esta serie puede observarse un leve dominio en la técnica de $\mathrm{Sa}$ [n] martín y [de] La Calle (Apéndice III, ejercicios 3 y 1).

La segunda serie se presenta, en su ejecución, a modo de ejercicio entre ambos opositores, en un careo e intercambios en la ejecución, de preguntas y respuestas. En su presentación escrita (Apéndice II, c[8] y e[8]; Apéndice III, Ejercicios 2a 2d) y su realización (Apéndice III, Ejercicios 3 y 3') el lector constata cierta confusión, debida en parte a la ausencia del Maestro de capilla; también se debe a la ausencia de firmas y del nombre de Pocurull en el papel de sus ejercicios. Hemos intentado resolver estas discordancias (Apéndice II, $c 8$ y e8 ; ejercicios 3 y 3'). Entre ambos opositores, más en el caso de Pocurull, se observa la prisa o el nerviosismo en concluir los ejercicios. En Pocurull se nota además una falta de dominio o madurez, notable tanto en las preguntas como en las respuestas. Además, en el Apéndice III, ejercicio 3 se nota una flojedad aguda en sus conocimientos modales. Teniendo en cuenta que al ejercicio I, a y b del mismo se le podría considerar como mediano la mediocridad de este ejercicio 3 le descalifica para el cargo al que aspira.

Por lo demás, no deja de sorprender la interpretación variable de ambos en torno a varios puntos teóricos. El empleo de las claves es distinto entre uno y otro. Pocurull emplea de modo sistemático la clave de Fa en tercera y diferencia el signo del compás mayor ( $\mathrm{C}$ partido con raya) del compasillo (C). Ambos coinciden en la escritura del tiempo de compasillo que transcribimos como un 4/2 para no alterar su contenido. Ambos dan también el mismo significado al tiempo de proporcioncilla (que reducimos a 6/2), pero parece que en su interpretación interna haya oscilaciones.

\section{D- ALGUNOS APUNTES COMPARATIVOS CON OTRAS ORGANISTÍAS}

La comparación de los ejercicos de estas oposiciones con otras de la misma centuria, aunque sean con mínimos y selecio- 
nados toques, es paso obligado. Así, si nos atenemos al ejercicio de 1622 sobre la ejecución de motetes y la reiteración documental meramente administrativa de 1699, el mencionado desuso observado en este repertorio no quiere decir que este ejercicio haya desaparecido del todo de las oposiciones a organista. En la catedral de Málaga, en 1663, fuera de las sesiones oficiales, el maestro de capilla Francisco Ruiz Samaniego "había llevado al pretendiente [Pedro de Aldao: tiene 20 años] a su casa y delante de algunos ministros de la iglesia le había hecho tocar dos motetes y le hizo algunas preguntas"17. Parece obvio que este ejercicio, oficioso y privado, es el mismo que, de modo oficial, se hizo en Salamanca en 1622. El carácter modélico y paradigmático de la obra vocal exigida, motete, ha de ponerse en relación con otra obra exigida, instrumental esta vez, en Valencia, por las mismas fechas del siglo XVII, el tiento ${ }^{18}$. La obra modélica de una época, vocal e instrumental (motete y tiento), se hace pues parangón para los estudiantes organistas de una época posterior a su propia formación y génesis.

Las oposiciones salmantinas de 1699 se sitúan entre el plan de ejercicios de Málaga del año 1663 y las de La Seo de Zaragoza, celebradas en 1730 y ganadas por Ignacio Subías, pero de las cuales sale elegido Joaquín Nebra, y que valdría comparar con las del Colegio del Corpus Christi de Valencia de 1677 [PRECIADO (1977)] ${ }^{19}$.

Los ejercicios de Málaga requieren las bondades exigidas de cualquier instrumentista desde Tomás de Santa María y, además, acompañamiento de voz o de otro instrumentista, transporte, acompañamiento de un motete para voz, acompañamiento de improviso de misas, salmos y villancicos, entender los preceptos de la composición para acompañar, ejecución fugada imitando en movimiento directo o contrario, misas, salmos... además de los intentos del autor. Los ejercicios de La Seo, además de más apretados (por ejemplo trasporte de un intento sobre las seis voces: Ut, Re, Mi, Fa, Sol, La), invierten igualmente su orden realzando las cualidades interpretativas de los candidatos:

- Ejecución de un lleno, partido de mano derecha e izquierda.

- Ejercicio teórico-práctico sobre las notas del hexacordo.

- Composición de una obra en un plazo de "24 horas", a partir de un intento dado y obligado.

- Ejecución de la misma.

- Improvisacion de un verso Ave maris Stella y cláusulas de 7 tonos, punto alto y después de la entonación por el sochantre de un Introito y Kyrie. En otra sesión de la oposición: trasporte del sexto punto bajo.

- Ejecución libre al órgano o en la cadereta (2 veces).

17 LLORDÉN (1968): 159.

18 PIEDRA (1962): 158.

19 El "Plan de los ejercicios contenido en el Libro de actas capitulares de La Seo y del Pilar del año 1730", nos lo comunica Pedro Calahorra el 06.01.1979. Después del artículo de Dionisio Preciado véase sobre todo el de EZQUERRO (2002b) que destaca el interés de estas oposiciones.
- Acompañamiento de un villancico a 8 y de un cuatro de dos versos de $8^{\circ}$ tono y de segundillo, así como el acompañamiento de una tonada.

- Canto por los músicos de un Kyrie e improvisación “por el intento".

- Ejecución de "música cromática".

En estos ejercicios zaragozanos del siglo XVIII se notan, además de la doble faceta del organista (acompañante y solista), notables cambios: una valoración mayor de las cualidades del músico-intérprete, una menor relevancia, aparente quizá, de la modalidad, la vigencia del "plato fuerte", que es la composición de una obra en 24 horas, que se supone sea reproducción de un modelo teórico. Naturalmente, y, no puede ser de otra forma, la orientación de la mayor parte de ellos sigue siendo la del papel del organista al servicio de la liturgia. Todo ello permite calibrar mejor y sopesar el valor de los candidatos. Pero aun no han aparecido en los ejercicios las nuevas formas ni, tampoco, atisbos del nuevo lenguaje de la tonalidad: el apego a las notas del hexacordo es lo suficientemente revelador; el nivel de los ejercicios prácticos (Apéndice III) de la oposición de [1699 deja obvia la distancia entre estos ejercicios y la realidad musical de este fin del siglo XVII vivida por los organistas compositores, por lo menos las más "modernos" de ellos, y entre éstos y la de las oposiciones zaragozanas de 1730.

\section{E- OPOSICIONES A ORGANISTÍA Y ORGANERÍA.}

Las oposiciones zaragozanas de 1730 dejan en claro la necesidad de lucimiento de los opositores en uno $\mathrm{u}$ otro organo, órgano mayor o cadereta con sus posibilidades respectivas. Ya en 1677 el informe de las oposiciones a organista del Colegio de Corpus Christi de Valencia sugiere que los opositores han de valer y contrastar sus habilidades en un ejercicio en que los dos órganos han de responderse uno al otro ${ }^{20}$. Pero no es así en Salamanca, que parece ignorar sus órganos en las oposiciones en 1622 o en 1699 (la memoria de Torres Rocha es abstracta): los ejercicios se hacen en un realejo, partido es verdad en 1699. Lo cierto también es que en 1700 los órganos salmantinos están "tan descompuestos, que demás de no estar en tono natural, si no es accidental, no se podía tocar en ellos por faltarles muchos registros...". Estos defectos se remedian en años posteriores en el órgano grande. Manuel de la Viña, encargado de su mantenimiento, perfecionna el órgano grande limpiando el instrumento y poniendo algunos registros de lengua en la fachada del coro, entre octubre de 1700 y 1702 , es decir, después de celebradas las oposiciones ${ }^{21}$. Introduce en ellos las novedades, o algunas de ellas, propias del órgano ibérico del segundo tercio del siglo XVII - como, por su propia iniciativa y sin contratar en las condiciones, el flautado

20 PIEDRA (1962): 155.

21 PÉREZ PRIETO (1995): 155-156. No detallan los textos conocidos todas las características técnicas de las aportaciones del organero Manuel de la Viña que se dan en BRESCIA (2013): I, 73-79. 
mayor, la trompeta real o trompeta magna - que no esperan la hechura del nuevo órgano de Liborna Echevarría de 1744 para prosperar [MARCOS \& ECHEVARRÍA (1987); GARCÍA FRAILE (2003)].

Las oposiciones salmantinas de 1699 parecen así, aparte el uso del realejo partido, organizarse como la memoria dejada por Torres Rocha/Micieces en abstracto. Se celebran fuera de las nuevas corrientes y realizaciones organólogicas emprendidas al oeste de la línea Eibar/Lerín/Sevilla por el clan de los Echevarría y sus discípulos, que se orientan hacia el suroeste o al noroeste. Concretamente Domingo Aguirre, que ha rematado el órgano palentino empezado por fray José Echevarría, su maestro y correligionario, está en Plasencia desde 1692. En 1694 se interesa por promover su nuevo instrumento para que luzca la "música moderna" que contiene. Entre los jóvenes organistas atraídos por sus posibilidades figura Pedro San Martín y de la Calle, organista en estos años de Medina del Campo, conocedor según Domingo Aguirre de la "escuela moderna" y de las posibilidades ténicas del nuevo instrumento. Domingo Aguirre lo recomienda al Cabildo de Plasencia pero quien lleva la plaza es Landa y Eraso, navarro que procede de Tafalla ${ }^{22}$. En Salamanca tampoco se puede medir su dominio de la "escuela moderna“ deseada por el organero Domingo Aguirre.

En 1699, cuando se le recibe en Salamanca, Pedro $\mathrm{Sa}[\mathrm{n}]$ martín y [de] Lacalle viene de Astorga, de cuya catedral es organista, después de haber hecho un "riguroso examen en Osma", en fecha que no se precisa. Su salida de Salamanca se anuncia en el Cabildo el $10.03 .1700^{23}$ por motivos que no se conocen: quizá no haya que descartar el deterioro de sus órganos en su decisión $^{24}$. El 22.05.1700 ${ }^{25}$ se recibe a Jacinto del Río [BARRIOS $(1999)]^{26}$, organista hasta este momento de la catedral de Coria, después de hacer sus ejercicios

"assí en composisión de Música, como en tocar en el Realejo que para d[ic]ho efecto estaba prebenido en la sala capitular tocando cossas determinadas que se le pidieron, y

22 GÓMEZ GUILLÉN (1980): 15. Nótese que en 1707 un "Greogrio Landa" o "Gregorio de Landa" es organista de los órganos de las iglesias de San Nicolás en 1687, de San Cernín de Pamplona en 1707-1708 que muere en 1720. Sin duda éste es hermano de Sebastián de Landa y Eraso, maestro de capilla y organista. Probablemente es éste el premiado aquí ya que ocupa el cargo de maestro de capilla por tres años de la iglesia de Santa María de Tafalla a partir del 03.09.1692. SAGASETA \& TABERNA (1985): 175, 292, 303, 310, 323, 377.

23 GÓMEZ GUILLÉN (1980): 15; y también MÉNDEZ HERNÁN (2007): 179.

24 Puede que sea el mismo Pedro San Martín que, en 1709, es organista de las Descalzas Reales de Madrid: SUBIRÁ (1957):150.

25 Con motivo de estas oposiciones el organista de Ciudad Rodrigo, Mateo Procorull [Pocurull], malogrado opositor contra Sa[n]martin y [de] Lacalle en 1699, escribió al cabildo de Salamanca, en mayo de 1700 o antes, para que se le tenga otra vez por opositor para la plaza de organista (E-SA, Actas capitulares 1695-1700, f.685r).

26 En Coria el organista entre 1698 y 1700 es Jacinto del Río, quien sucede a Juan Mateos Avellano. otras que se dejaron a su elección y gusto, y respondiendo a las preguntas que en todo se le hicieron por el S. $\mathrm{R}^{\circ} \mathrm{D}$. thomas de Miziezes Maestro de capilla hasta que el cav ${ }^{\circ}$ mandó que cessasse" 27 .

Jacinto del Río se despedirá del cabildo de Salamanca el $16.03 .1714^{28}$, para ir a Toledo tomar cargo de sus órganos catedralicios después de su elección el 28.02.1714²9.

Las oposiciones a la organistía salmantina en el siglo XVII son escasas (1622 y 1699 con una etapa intermedia de 1679) y muy limitadas en su expansión territorial (no pasan de dos catedrales exteriores en 1699), pero aleccionadoras en su significado. En ambas oposiciones destaca el papel de los dos niveles del tribunal, respaldado por su condición de miembros de "voz y voto", pero se ha subrayado el de los asesores de los mismos, músicos que habrán desempeñado un papel difícil de valorar, que transmiten también al cabildo el pulso de las prácticas y realidades musicales. Del órgano lleno de un teclado de principios de siglo la catedral ha pasado al órgano partido, aunque no haya incorporado aún las innovaciones de finales de siglo. Así de unos ejercicios propios del siglo XVI (el "poner en el monacordio") a los opositores se les exige obras del pleno XVII (obras partidas de una o dos voces bajas o altas). También se les exige primero que dominen su papel: el servir una liturgia, un culto, el de la iglesia católica. El siglo XVII llega a puntualizar y multiplicar, como es notable en el plan de oposiciones 1679 , los ejercicios de acompañamiento en los cuales el opositor no deja de lucir su calidad de tañedor y de cantante. Y esto lo desenvuelve tanto en el canto monódico o modal, es decir en cuanto a sus conocimientos modales, como en el canto polifónico o figurado, tocante a sus conocimientos de la escritura de canto de órgano. Parece pues que los ejercicios acompañan la evolución de la música del siglo XVII aunque no llegan a suscitar realidades instrumentales propias de su tiempo. Esto parece aún más evidente si se consideran los ejercicios realizados "con pluma" que han llegado hasta nosotros. Son testimonios de la solidez, o no, de sus conocimientos y de su aptitud y capacidad a desempeñar el cargo que se les ofrece. En el caso de 1622 está claro que se les pide un mayor dominio de la escritura vocal que de su instrumento, pero en ambos casos, 1622 o 1699, tampoco son el lugar idóneo para desarrollar su capacidad de invención e innovación. En todo caso las oposiciones salmantinas son un verdadero reflejo, totalmente contemporáneo, de la evolución musical e instrumental del siglo, para lo que se instituyeron, pero también son el reflejo rezagado y poco vivificante de las prácticas contemporáneas ${ }^{30}$.

$27 \boldsymbol{E}$-SA, Actas capitulares 1695-1700, fol.685 r.

$28 \boldsymbol{E}$-SA, Actas capitulares 1710-1715, fol. 136r.

29 RUBIO PIQUERAS (1923): 66, 103.

$30 \mathrm{Mi}$ más profundo agradecimiento a Josefa Montero por haberme guiado en mi investigación en el archivo de música de la catedral salmantina. 
Miembros del tribunal técnico: Sebastián de Vivanco, maestro de capilla, organistas de los monasterios de San Agustín, San Francisco y Santo Domingo.

Racioneros cantores: Moreno, Floriano, Valentín, Ramírez, Castro.

Número de votos del tribunal institucional (Cabildo): 44

\begin{tabular}{|c|c|c|c|c|c|c|}
\hline Apellido & Nombre & $\begin{array}{c}\text { Procedencia } \\
\text { Catedral }\end{array}$ & $\begin{array}{c}\text { Procedencia } \\
\text { Colegial }\end{array}$ & Título & Votos & Elección \\
\hline Alvarez & Juan & & Talavera de la Reina & Racionero & 4 & \\
\hline Nieto & Pedro & Coria & & Racionero & 0 & \\
\hline Salazar & Pedro & Astorga & & Racionero & 1 & \\
\hline Herrera & Hernando de & Palencia & & Racionero & 2 & \\
\hline Torres & Antonio de & Oviedo & & Racionero & 1 & Racionero \\
\hline Nieto & Manuel & Santiago de Compostela & & 36 & Elegido \\
\hline
\end{tabular}

Figura 1. Salamanca. Oposiciones a organista de 6 y 7 de mayo de 1622

Miembros del tribunal técnico: Tomás de Micieces, maestro de capilla [se disculpa que no participe activamente por ser cuñado de Pedro Sa[n]martín y [de] Lacalle], Diego Camero de Vitoria, Pedro de Pineda.

Racioneros cantores: Marcos Castañón, Santiago de Ribera, Francisco García, Domingo García, Nicolás de Ayundoaga, Caspar de Unsaluarte, Miguel de Castellanos Montenegro.

Número de votos del tribunal institucional (Cabildo): 43.

\begin{tabular}{|c|c|c|c|c|c|c|}
\hline Apellido & Nombre & $\begin{array}{c}\text { Procedencia } \\
\text { Catedral }\end{array}$ & $\begin{array}{c}\text { Procedencia } \\
\text { Colegial }\end{array}$ & Título & Votos & Elección \\
\hline $\mathrm{Sa}[\mathrm{n}] \mathrm{martin}$ y $[\mathrm{de}] \mathrm{La}$ Calle & Pedro & Astorga & & organista & 29 & $\mathrm{Elegido}$ \\
\hline Pocorull & Matheo & Ciudad Rodrigo & & organista & 14 & \\
\hline
\end{tabular}

Figura 2. Salamanca. Oposiciones a organista de los días 11, 12, 14, 16 y 17 de noviembre de 1699

\section{BIBLIOGRAFÍA}

Archivo de la catedral de Ávila $(\boldsymbol{E}$-Ac), Legajo 3/ n 124, Capellanías Raciones y Canonicatos, Año de 1605. Contralto y Organista.

Archivo de la catedral de Salamanca $(\boldsymbol{E}-S A)$, cajón 48, leg. 2, $\mathrm{n}^{\circ} 1 \mathrm{y} \mathrm{n}^{\circ} 20$.

Archivo de la catedral de Salamanca (E-SA), Actas capitulares de la catedral de Salamanca 1616-1630, fol. 30r -01.03.1622- y 61r. -04.03.1622-.

Artero, José, "Oposiciones al Magisterio de Capilla en España durante el siglo XVIII”. Anuario Musical, 2 (1947): 191-202.

Barrios Manzano, María del Pilar, La música en la catedral de Coria. 1590-1755, Cáceres, Universidad de Extremadura, 1999.

Bourligueux, Guy, "Unas oposiciones al Magisterio de Capilla de la Catedral de Oviedo a principios del siglo pasado", Boletín del Instituto de Estudios Asturianos, XLIX (1970), 3-17.
Brescia, Marco, "Manuel de la Viña, maestro de órganos vecino de Salamanca: eslabón entre la escuela Echevarría y la organería desarrollada en el nordeste de la Península en la primera mitad del siglo XVIII", (Marín López, Javier; Gan Quesada, Germán; Torres Clemente, Elene; y Ramos López, Pilar; coords.) $M u$ sicología global, musicología local. Madrid, Sociedad Española de Musicología, 2013, 2377-2394. [Disponible en línea: https://docs.wixstatic.com/ugd/e92088 _62dfe76f32894ad4b570448414609086.pdf (Acceso, 15.01.2018).

Brescia, Marco, L'école Echevarría en Galice et son rayonnement au Portugal. Tesis doctoral, París, Université de Paris-Sorbonne 2, 2013, I, 73-79.

Calahorra Martínez, Pedro, La musica en Zaragoza. Siglos XVIXVII. Polifonistas y Ministriles. Zaragoza, Institución "Fernando el Católico”, 1978, 349, 352, 355, 357-358, 360.

Casares Rodicio, Emilio: "Doyagüe Jiménez. 1. Carlos Florencio. 2. Manuel José”, en Diccionario de la Música Es- 
pañola e Hispanoamericana. (Casares Rodicio, Emilio, dir.). Madrid, SGAE, vol. 4, 1999, 539-542.

Cerone, Pedro: El Melopeo y Maestro. Nápoles, Juan Bautista Gargano y Lucrecio Nucci, 1613. (Ezquerro Esteban, Antonio, ed.). 2 vols. Barcelona, CSIC, col. "Monumentos de la Música Española, LXXV”, 2007.

Cruz, Javier, "Fernando de Herrera: organista de la Universidad y la Catedral de Salamanca durante gran parte del siglo XVII", Sebastián Durón (1660-1716) (Capdepón Verdú, Paulino; y Pastor Comín, Juan José; eds.). Vigo, Academia del Hispanismo, 2013, 299-305.

Eximeno Pujades, Antonio, Don Lazarillo Vizcardi: sus investigaciones músicas con ocasión del concurso a un magisterio de capilla vacante. Madrid, Sociedad de Bibliófilos Españoles, Imp. M. Rivadeneyra, 1873.

Ezquerro Esteban, Antonio, "Torres [Rocha?], Juan de", Diccionario de Música Española e Hispanoamericana (Casares, Emilio, dir.). Madrid, SGAE, vol. 10, 2002, 401-404. [2002a]

Ezquerro Esteban, Antonio, "Nuevos datos para el estudio de los músicos Nebra en Aragón”, Anuario Musical, 57 (2002), 131-141. [2002b]

Garbayo Montabes, Francisco Javier, “Artero, José”, Diccionario de Música Española e Hispanoamericana (Casares, Emilio, dir.). Madrid, SGAE, vol. 1, 1999, 780.

Garbayo Montabes, Francisco Javier, “José Artero (1890-1961), cronista exégeta e ideólogo del Motu Propio en España”, Revista de Musicología, XXVII/1 (2004), 523-551.

García Fraile, Dámaso, "Gaspar Sanz, catedrático frustrado de la Universidad de Salamanca", en De Musica Hispana et aliis, Miscelánea en honor al Prof. Dr. José López-Calo, S. J., en su 65 cumpleaños. (Casares Rodicio, Emilio; y Villanueva Abelairas, Carlos; coords.). Santiago de Compostela, Universidad de Santiago de Compostela, 1990, I, 593-603.

García Fraile, Dámaso, Francisco Olivares (1779-1854). Once conciertos para dos órganos. Estudio y edición crítica. Valladolid, Fundación Las Edades del Hombre, XII, 2003.

Gómez Guillén, Román, Los órganos de la catedral de Plasencia. Datos para un estudio histórico. Cáceres, Ministerio de Cultura Delegación provincial de Cáceres, 1980.

Llordén Simón, Andrés, "Notas históricas de los maestros organistas de la catedral de Málaga", Anuario Musical, XXIII (1968), 159.

Lu, Julia; y Dratwicki, Alexandre (coords.), Le concours du Prix de Rome de musique (1803-1968). Lyon, Symétrie, 2011.

Marcos Rodríguez, Florencio; y Echevarría, Lamberto de, Los órganos de la catedrales de Salamanca. Salamanca, Universidad Pontificia de Salamanca, Centro de Estudios Salmantinos, 1987.

Martín González, José, "Oposiciones al magisterio de capilla de la catedral de Valladolid durante el siglo XIX", Revista de Musicología, 14/1-3 (1991), 511-534.

Martínez Gil, Carlos, La oposición a la ración de organista principal de la catedral de Toledo en 1765. Toledo, Ca- bildo Primado, Catedal de Toledo, col. "Primatialis Ecclesiae Toletane Memoria”, 2016.

Méndez Hernán, Vicente. Maestros de hacer órganos en la provincia de Cáceres. Siglos XVI-XX. Cáceres, El Brocense 2007.

Pérez Prieto, Mariano, "La capilla de música de la catedral de Salamanca durante el período 1700-1750: historia y estructura”, Revista de Musicología, XVIII/1-2,(1995), 145-174.

Personat Remolar, Alfredo, Juan Moreno y Polo (1711-1776). Dos Salmodias para misas -versos para lleno-. Santo Domingo de la Calzada, Fundación Gustavo Bueno, Serie Partituras/Colección Ars Hispana, 2013.

Piedra Miralles, Joaquín, "Organistas valencianos de los siglos XVII y XVIII. A) Organistas del Colegio de Corpus Christi”, Anuario Musical, 17 (1962), 141-178.

Preciado Ruiz de Alegría, Dionisio, "Francisco de Peraza II, vencedor de Francisco Correa Araujo", Tesoro Sacro Musical, 611/1 (1970), 9-11.

Preciado Ruiz de Alegría, Dionisio, "Joaquín Nebra (17091782). 52 años largos de organista en la Seo de Zaragoza (1730-1782)", Tesoro Sacro Musical, 639/1 (1977), 12-17.

Reynaud, François, La polyphonie tolédane et son milieu des premiers témoignages aux environs de 1600. París-Turnhout, CNRS-Brepols, 1996.

Rodríguez Pablo L., “... En virtud de bulas, y privilegios apostólicos: Expedientes de oposición a maestro de capilla y a organista en la catedral de Zamora", Anuario del Instituto de Estudios Zamoranos "Florián de Ocampo", 11 (1994), 409-479.

Rubio Piqueras, Felipe, Música y músicos toledanos. Toledo, Estab. Tip. de Sucesor de J. Peláez, 1923.

Sagaseta Aríztegui, Aurelio; y Taberna Tompes, Luis, Órganos en Navarra. Pamplona, Ed. Gobierno de Navarra, 1985.

Subirá Puig, José. "La música en la Capilla y Monasterio de las Descalzas Reales de Madrid", Anuario Musical, 12 (1957), 147-166.

Torrente Sánchez-Guisande, Álvaro, "Cuestiones en torno a la circulación de los músicos catedralicios en la España moderna", Artigrama, 12 [Zaragoza, Departamento de Historia del Arte de la Universidad de Zaragoza] (19961997), 217-236.

Villanueva Abelairas, Carlos, "Villancico", Diccionario de la Música Española e Hispanoamericana (Casares Rodicio, dir.). Madrid, SGAE, vol. 10, 2002, 922.

\section{APÉNDICES}

Salamanca. Archivo de la catedral

\section{I-OPOSICIONES A LA ORGANISTÍA DE 1622 Cajón 48, legajo2/1}

a) Cavildo en q[ue] los opositores començaron a haçer sus exerçicios y a ser examinados.

En la Çiudad de salam ${ }^{\text {ca }}$ biernes seis dias de mayo de mill y seisçientos y veinte y dos añs los señores Dean y Cavildo de la $\mathrm{S}^{\text {ta }} \mathrm{yg}^{\mathrm{a}}$ cathedral de la d[ic]ha Çiudad estando juntos segun y 
en la parte $\mathrm{q}[\mathrm{ue}]$ lo acostumbran y presentes señores Dignidades canonigos Raçioneros y medios Raçioneros q[ue] por ser muchos y evitar prolixidad aqui no se expressan sus nombres y presidiendo especialmente el señor Doctor Don geronimo de chiriboga Dean y Canonigo de la d[ic]ha sancta yglessia, y estando ansi juntos ante mi Pedro Roman notario $\mathrm{pu}^{\mathrm{co}} \mathrm{app}^{\mathrm{co}}$ y su s ${ }^{\circ}$ el d[ic]ho señor Dean propuso al d[ic]ho Cavildo que para este dia estaba diferido el tratar de la probission de la prebenda de organista de esta sancta yglessia por ser pasado el termino de los edictos y q[ue] los opositores avian de ser examinados q[ue] el Cavildo ordenase y mandase lo $\mathrm{q}[\mathrm{ue}]$ fuese servido= y hecha la $\mathrm{d}[\mathrm{ic}]$ ha proposicion estando presentes el señor maestro Vivanco maestro de capilla de la ${ }^{\text {ta }}$ yglessia y tres Religiosos organistas de las ordenes de Sancto Domingo, san françisco y san Agustín que para asistir al d[ic]ho examen avian sido llamados y para informar de la justiçia de los opositores= el Cavildo mando y ordeno fuesen examinados y q[ue] cada uno hiçiese sus exerçicios y para el $\mathrm{d}[\mathrm{ic}]$ ho effecto fuesen entrando por sus antiguedades en el d[ic]ho Cavildo y tocasen los motetes q[ue] por el d[ic]ho señor maestro de Capilla se les ordenase y poniendose en execuçion lo susod[ic] ho entro primeramente [al margen: talabera] Juan Albarez Raçionero de la yglesia de talabera y en un rrealexo q[ue] estaba dentro de la sala del d[ic]ho Cavildo para el $\mathrm{d}[\mathrm{ic}]$ ho effecto hiço los exerçiçios y toco los motetes q[ue] por el d[ic]ho señor maestro de capilla le fueron ordenados y con ello se salio fuera del $\mathrm{d}[\mathrm{ic}]$ ho $\mathrm{C}^{\mathrm{vo}}=[$ al margen: Coria $]$ y luego fue mandado llamar y entro en el d[ic]ho Cavildo Pedro nieto Raçionero de la sancta yglessia de Coria y hiço los mismos exerçiçios y toco los mismos motetes segun por el d[ic]ho señor maestro de capilla le fue ordenado y se salio de la d[ic]ha sala-

[Al margen: Astorga] Y luego entro Pedro de salaçar Raçionero de la sancta ylessia de Astorga y hiço lo mismo-----

[Al margen: Palençia] Y luego entro Hernando de Herrera Raçionero de la sancta yglessia de Palençia y hiço los mismos exerçiçios y se salio fuera del d[ic]ho Cavildo------

[Al margen: Oviedo] Y luego entro Antonio de Torres Raçionero de la $\mathrm{s}^{\text {ta }} \mathrm{yg}^{\mathrm{a}}$ de Oviedo y hiço lo mismo-

[Al margen:Santiago] y luego entro manuel nieto Raçionero de la sancta yglesia de santiago de galiçia y hiço los mismos exerçiçios y toco los mismos motetes segun por el d[ic]ho señor maestro de capilla le fue ordenado y se salio de la d[ic]ha sala----

$\mathrm{Y}$ hechos los $\mathrm{d}[\mathrm{ic}]$ hos exerçiçios y examen el $\mathrm{C}^{\mathrm{vo}}$ mando informasen y diesen su pareçer los $\mathrm{d}[\mathrm{ic}] \mathrm{hos}$ padres Religiosos organistas q[ue] estaban presentes y en primero lugar informo el padre Dominico y dijo q[ue] le avian pareçido tocaban mejor y que avian salido mas bien de $\mathrm{d}$ [ic]ho examen y de mejores abilidades los opositores de santiago de galiçia, Coria y Talabera a quien puso en mejor lugar declarando q[ue] qualquiera de ellos mereçia la d[ic]ha Raçion-------

Y luego aviendo mandado el Cavildo informasen los padres Religiosos de san Agustín y san françisco dixeron tenían mandato expresso de su superior para no dar su pareçer en publico q[ue] en secreto estaban prestos de haçerlo=---

Y luego incontinenti el Cavildo aviendose salido fuera de el los $\mathrm{d}$ [ic]hos padres mando informase el $\mathrm{d}[$ ic $]$ ho $\mathrm{s}^{\mathrm{r}}$ maestro de capilla el qual propuso a los $\mathrm{d}[\mathrm{ic}]$ hos señores Dean y Cavildo $\mathrm{q}[\mathrm{ue}]$ en este negoçio por ningun caso se podía tomar luego rresoluçion ni su $\mathrm{m}^{\mathrm{d}}$ dar su pareçer hasta $\mathrm{q}[\mathrm{ue}] \operatorname{los} \mathrm{d}[\mathrm{ic}]$ hos opositores hiçiesen mas exerçiçios en $\mathrm{q}[\mathrm{ue}]$ se mostrasen y pareçiesen mas sus abilidades y q[ue] combenia suspender la d[ic] ha probision hasta mañana sabado siete de este presente mas y año para quando traeran sus motetes estudiados q[ue] para ello les dara luego con $\mathrm{q}[\mathrm{ue}]$ mejor y con mas satisfacçion se hara la $\mathrm{d}[\mathrm{ic}] \mathrm{ha}$ probission = el Cavilo por la d[ic]ha Raçon lo suspendio hasta mañana y mando $\mathrm{q}[\mathrm{ue}]$ el $\mathrm{d}[\mathrm{ic}]$ ho $\mathrm{s}^{\mathrm{r}}$ maestro de capilla les de luego los $\mathrm{d}[\mathrm{ic}]$ hos motetes para $\mathrm{q}[\mathrm{ue}]$ los traigan estudiados $\mathrm{y}$ los toquen y hagan muebos exerçiçios con lo qual se lebanto el $\mathrm{d}[\mathrm{ic}]$ ho $\mathrm{Cav}^{\mathrm{o}} \mathrm{y}$ en fee de ello lo firme $=$

Ante mi Pedro Roman $n^{\circ}$ y s$^{\circ}$

b) Cavildo en q[ue] se probeyo la Raçion de organista

En la d[ic]ha Çiudad de salamanca sabado siete dias del $\mathrm{d}[\mathrm{ic}]$ ho mes de mayo y año de seisçientos y veinte y dos los $\mathrm{d}[\mathrm{ic}]$ hos señores Dean y Cavildo de la $\mathrm{d}[\mathrm{ic}]$ ha $\mathrm{s}^{\text {ta }} \mathrm{yg}^{\mathrm{a}}$ cathedral de Salamanca estando juntos en su $\mathrm{Cav}^{\circ}$ segun y en la parte $\mathrm{q}[\mathrm{ue}]$ lo acostumbran y presidiendo en el el $\mathrm{d}[\mathrm{ic}]$ ho $\mathrm{s}^{\mathrm{r}}$ Doctor don ger $^{\text {mo }}$ de chiriboga Dean y can ${ }^{\circ}$ de la d[ic]ha $s^{\text {ta }}$ yg $^{\text {a }}$ ante mi el d[ic]ho Pedro Roman not ${ }^{\circ}$ y s $^{\circ}$ susod[ic] ho dijeron $\mathrm{q}[\mathrm{ue}]$ para este dia ultimamente estaba diferido la probision de la Raçion y prebenda [entre rayas : de organista] de esta $\mathrm{s}^{\text {ta }} \mathrm{yg}^{\mathrm{a}} \mathrm{y}$ q[ue] para $\mathrm{q}$ [ue] se hiçiese con la justificaçion y satisfaçion neçessaria combenia q[ue] todos los opositores entrasen en el d[ic]ho $\mathrm{Cav}^{\mathrm{o}}$ a tocar en el rrealejo q[ue] en el estaba los motetes q[ue] por el $\mathrm{S}^{\mathrm{r}}$ maestro de capilla de esta $\mathrm{s}^{\text {ta }}$ yglessia se les avian dado y traian estudiados y assi mando el $\mathrm{Cav}^{\circ}$ fuessen entrando los d[ic]hos opositores para el d[ic]ho effecto como en effecto cada uno por su antiguedad entraron y tocaron en el d[ic]ho rrealejo los d[ic] hos motetes $=\mathrm{y}$ acabado de tocar el $\mathrm{d}[\mathrm{ic}]$ ho $\mathrm{s}^{\mathrm{r}}$ maestro de capilla hiço rrelaçion como los d[ic]hos opositores avian ya hecho el exerçiçio q[ue] les avia ordenando y q[ue] le pareçia q[ue] mas satisfacçion y mejor conocimiento de las abilidades de cada uno si quieresen tocasen mas mostrando sus abilidades- y el $\mathrm{Cav}^{\mathrm{o}}$ mando q[ue] ansi lo hiçiessen- y aviendo començado a haçer los $\mathrm{d}[\mathrm{ic}]$ hos muebos actos y exerçiçios por algunos incombinientes e inquietudes q[ue] començo a aver entre los opositores mando el $\mathrm{Cav}^{\circ}$ çesassen y q[ue] todos se saliesen fuera de la sala del $\mathrm{d}[\mathrm{ic}]$ ho $\mathrm{Cav}^{\circ}$ como en effecto se salieron $=$ Y luego incontinenti el d[ic]ho $\mathrm{s}^{\mathrm{r}}$ maestro de Capilla informado de las abilidades de los $\mathrm{d}[\mathrm{ic}]$ hos opositores dijo q[ue] su pareçer era q[ue] los $\mathrm{q}[\mathrm{ue}]$ avian salido mas abentajadamente con sus exerçiçios y aun casi con ygualdad era el de santiago de galiçia= el de Ovie$\mathrm{do}=\mathrm{el}$ de Palençia= y el de Astorga, y q[ue] en qualquiera de ellos se probeeria justamente la $\mathrm{d}[\mathrm{ic}] \mathrm{ha}$ Raçion y prebenda y particularmente y en primero lugar puso al de santiago por aver salido mas abentajadamente y con mas satisfacçion de todos sus exerçiçios---------

Y hecha la d[ic]ha ynfor ${ }^{\text {on }}$ el $\mathrm{Cav}^{\circ}$ mando q[ue] los d[ic] hos opositores fuesen entrando a informar de su justicia como en effecto entraron por sus antiguedades y lo hiçieron y algunos presentaron trestimonios de lo q[ue] goçaban en su sa $\mathrm{yg}^{\mathrm{a}}$ y luego el $\mathrm{d}[\mathrm{ic}]$ ho $\mathrm{Cav}^{\circ}$ mando q[ue] los señores Raçioneros cantores q[ue] 
estaban presentes ansimismo informasen y diesen su pareçer $=\mathrm{y}$ en cumplimiento del d[ich]o mandato el $\mathrm{s}^{\mathrm{r}} \mathrm{Ra}^{\mathrm{o}}$ moreno dijo q[ue] le parecia lo mismo q[ue] al s ${ }^{r}$ maestro de capilla=---------

Y luego los $\mathrm{s}^{\text {es }}$ Raçioneros floriano y balentin dijeron $\mathrm{q}[\mathrm{ue}]$ en su voto secreto darían su pareçer-----

Y luego el $\mathrm{s}^{\mathrm{r}} \mathrm{Ra}^{\mathrm{o}}$ Ramírez informo q[ue] Juan albarez $\mathrm{Ra}^{\mathrm{o}}$ de la yg $^{\text {a }}$ de talabera acompañaba y tocaba mui bien y q[ue] en conçiençia mereçía la d[ic]ha prebenda y se debía dar al de santiago por abentajar a todos los opositores

$\mathrm{El} \mathrm{s}{ }^{\mathrm{r}} \mathrm{Ra}^{\circ}$ Castro informo y puso en mejor lugar al de santiago y al de astorga y q[ue] Juan albarez acompañaba mui bien y todos mereçian la prebenda $\mathrm{q}[\mathrm{ue}] \mathrm{el} \mathrm{Cav}^{\circ}$ hiçiese lo q[ue] fuese servido------

Y hechas las d[ic]has informaçiones y abiendose salido fuera del d[ic]ho $\mathrm{Cav}^{\circ}$ el d[ic]ho $\mathrm{s}^{\mathrm{r}}$ maestro de capilla el $\mathrm{Cav}^{\mathrm{o}}$ mando a mi el pres ${ }^{\text {te }} \operatorname{not}^{\mathrm{o}} \mathrm{y} \mathrm{s}^{\mathrm{o}}$ fuese dando cedulas a todos los $\mathrm{s}^{\mathrm{es}}$ $\mathrm{q}[\mathrm{ue}]$ estaban presentes para $\mathrm{q}[\mathrm{ue}]$ se votase la $\mathrm{d}[\mathrm{ic}]$ ha elecçion y probission y yo el $\mathrm{d}[\mathrm{ic}]$ ho not $^{\circ} \mathrm{y} \mathrm{s}^{\circ}$ entregue a cada uno de los $\mathrm{d}[\mathrm{ic}]$ hos señores seis cedulas en $\mathrm{q}[\mathrm{ue}]$ iban puestos los nombres de los $\mathrm{d}[\mathrm{ic}]$ hos seis opossitores y aviendo hecho el juramento acostumbrado de votar por el q[ue] pareçiese mas benemerito al serviçio de Dios y de la yg ${ }^{a}$ fueron votando con las d[ic]has çedulas al altar en la caja donde se vota por haba y altramuz= y acabado de votar se rregularon los votos y tubo manuel nieto Raçionero de la s ${ }^{\text {ta }} \mathrm{yg}^{\mathrm{a}}$ de santiago de galiçia treinta y seis votos $=$ y Juan Albarez $\mathrm{Ra}^{\circ} \mathrm{de}$ la $\mathrm{yg}^{\mathrm{a}} \mathrm{de}$ talabera quatro votos $=\mathrm{y}$ Hernando de Herrera Raçionero de la s $^{\text {ta }} y^{\text {a }}$ de Palençia dos votos= y Antonio de Torres Raçionero de la $\mathrm{s}^{\text {ta }} \mathrm{yg}^{\mathrm{a}}$ de Oviedo un voto= y Pedro de Salaçar Racionero de la $\mathrm{s}^{\text {ta }} \mathrm{yg}^{\mathrm{a}}$ de Astorga otro= de manera $\mathrm{q}[\mathrm{ue}]$ de primero escrutinio llebo la d[ic]ha Raçion y prebenda por tener mas votos el d[ic]ho manuel nieto $\mathrm{Ra}^{\mathrm{o}}$ de la $\mathrm{s}^{\text {ta }} \mathrm{yg}^{\mathrm{a}}$ de santiago $=\mathrm{y}$ el $\mathrm{d}[\mathrm{ic}]$ ho Pedro nieto $\mathrm{Ra}^{\mathrm{o}}$ de la $\mathrm{s}^{\text {ta }} \mathrm{yg}^{\mathrm{a}}$ de Coria no tubo ninguno=

Y luego incontinenti los d[ic]hos $\mathrm{s}^{\mathrm{es}}$ Dean y $\mathrm{Cav}^{\mathrm{o}}$ mandaron a mi el presente not $^{\circ} \mathrm{y} \mathrm{s}^{\mathrm{o}}$ saliese a dar la nueba al d[ic]ho Pedro [sic] nieto y le llamase para q[ue] fuese al d[ic]ho $\mathrm{Cav}^{\circ}$ y se le encomendase como se acostumbra la d[ic]ha Raçion y prebenda $=\mathrm{y}$ aviendole llamado entro en el $\mathrm{d}[\mathrm{ic}] \mathrm{ho} \mathrm{Cav}^{\mathrm{o}} \mathrm{y}$ dio las gracias a los $\mathrm{d}[\mathrm{ic}]$ ho señores por la $\mathrm{m}^{\mathrm{d}} \mathrm{y}$ honrra $\mathrm{q}[\mathrm{ue}]$ le avian hecho $=\mathrm{y}$ aviendose incado de Rodillas delante del $\mathrm{s}^{\mathrm{r}}$ Dean y $\mathrm{Ca}^{\mathrm{o}}$ le dio y encomendo la d[ic]ha Raçion y prebenda de organista de la $d[i c]$ ha $\mathrm{s}^{\text {ta }} \mathrm{yg}^{\mathrm{a}}$ conforme a la bulla de su erecçion y el $\mathrm{s}^{\mathrm{r}}$ Dean en señal de la $\mathrm{d}[\mathrm{ic}] \mathrm{h}$ a encomienda le puso un bonete en la cabeça $=$ y el $\mathrm{Cav}^{\circ}$ le dio liçençia para q[ue] por agora y con toda la brebedad vaya a cumplir con su $\mathrm{y}^{\mathrm{ga}}$ de santiago y vuelva a servir y rresidir su prebenda de esta $\mathrm{s}^{\text {ta }} \mathrm{yg}^{\mathrm{a}}{ }^{----}$

Y luego incontinenti se propuso q[ue] era neçessario $\mathrm{q}[\mathrm{ue}]$ a los demas opositores se les diese algun dinero para ayuda al gasto de su camino y assi aviendose votado in voce y por aba y altramuz [....Falta un folio $\sin d u d a]$

\section{II- OPOSICIONES A LA ORGANISTÍA DE 1699. Cajón 48, legajo 3, n⿳3/20}

a) $\mathrm{Cau}^{\mathrm{do}}$ en que se dio por cumplido el termino de los edictos y se señalo dia para que los oppossitores hiçiessen ejerçiçios.
En el $\mathrm{Cau}^{\mathrm{do}}$ ordinario que se hiço en la Santa Yglesia de Salam ${ }^{a}$ miercoles Onçe de Noviembre de Mill Seiçientos y nobenta y nuebe años, en que Presidio el $\mathrm{s}^{\mathrm{r}} \mathrm{D}^{\mathrm{r}} \mathrm{D}^{\mathrm{n}}$ enrrique escon y enrriquez Dean y $\mathrm{Can}^{\circ}$ de la Santa Yglesia y presentes Muchos $\mathrm{s}^{\text {res }}$ Dignidades Canonigos Racioneros enteros, Medios Racioneros juntos en su sala Capitular como lo tienen de costumbre, yo el secretario de d[hos] $\mathrm{s}^{\text {res }}$ di quenta como el termino de los quarenta dias de los edictos despachados para la prouission de la Media Racion de Organista de d[ic]ha ${ }^{\text {ta }}$ Yglesia Vacante por muerte de D. franco Sanz de tejeda su ultimo posehedor se habia cumplido el Lunes passado nuebe de este pressente mes inclussiue. Y el Cauildo lo declaro por Cumplido y à causa de estar opuestos $\mathrm{D}^{\mathrm{n}}$ Pedro de Sa[n]Martin y [de] La Calle Organista de la $\mathrm{s}^{\text {ta }}$ yglesia Cathedral de la Çiudad de Astorga y $\mathrm{D}^{\mathrm{n}}$ Matheo Pocurüll Organista de la santa Yglesia de Çiudad Rodrigo, y hacerseles mala obra en detenerlos por la falta que harian en sus yglesias, y que podian ser oidos y examinados, y bolberse a sus Yglesias, suspendiendo la prouission de la d[ic]ha Media Raçion hasta que Viniessen otros oppossitores que se esperaban ; acordo el Cauildo, que desde mañana Juebes doçe de este mes se bayan haçiendo los Cauildos sobra [=extra]Ordinarios que fueren neçesarios, y en ellos bayan entrando assi los d[ic] hos dos oppossitores, como los demas que vinieren a açer sus ejerçicios y ser examinados, y tocar los motetes que les fueren señalados : para que assi ejecutado puedan si quisieren bolberse a sus Yglesias, hasta que llegue el casso de prouehersse le d[ic] ha Media Raçion de Organista, con lo qual se acabo este Cauildo de que doy fee y lo firme=

Ante mi Joseph martin de la fuente.

b) $\underline{\mathrm{Cau}}^{\mathrm{do}}$ en que los opossitores començaron a hacer sus ejerçicios.

En el $\mathrm{cau}^{\mathrm{do}}$ estra Ordi $^{\circ}$ que se hiço en la $\mathrm{s}^{\text {ta }}$ Yglesia de Salam $^{\mathrm{a}}$ juebes doçe de Nobiembre de Mill y Seisçientos y nobenta y nuebe años, en que Presidio el $\mathrm{s}^{\mathrm{r}} \mathrm{D}^{\mathrm{r}} \mathrm{D}^{\mathrm{n}}$ enrrique ezcon y enrriquez Dean y $\mathrm{Can}^{\circ}$ de la Santa Yglesia y Pressentes muchos ${ }^{\text {res }}$ Dignidades, Canonigos, Racioneros Enteros, Y Medios Raçioneros , Juntos y Congregados en su Sala Capitular, como lo tienen de Usso y Costumbre en conformidad de lo acordado, en el Cauildo antecedente, acordo y mando el Cauildo que los Oppossitores a la Media Raçion de Organista de d[ic]ha Santa Yglesia Vacante por muerte de $\mathrm{d}^{\mathrm{n}}$ fran ${ }^{\mathrm{co}}$ sanz de texada su ultimo posehedor fuessen entrando por sus antiguedades, entrando primero el mas moderno, a haçer sus ejerçiçios y ser examinados, y tocar los motetes que les fuessen señalados, y por el $\mathrm{s}^{\mathrm{r}}$ $\mathrm{R}^{\mathrm{o}} \mathrm{D}^{\mathrm{n}}$ Thomas de miziezes Maestro de Capilla de d[ic]ha Santa Yglesia, les fuesse ordenado, y acaussa de que $\mathrm{D}^{\mathrm{n}}$ Pedro de Samartin y La Calle al pressente presbitero, habia estado cassado con hermana de d[ic]ho Maestro de Capilla, d[ic]ho s ${ }^{\mathrm{r}}$ Maestro supplico al Cauildo se siruiesse de ternerle por excussado, y excussarle de que hiçiesse las preguntas a los oppositores ; à cuio tiempo el $\mathrm{s}^{\mathrm{r}} \mathrm{R}^{\mathrm{o}} \mathrm{D}$. Pedro de Pineda Prebendado de d[ic]ha Santa Yglesia, ynteligente en la Mussica, dijo tenia una Memoria [al margen: Preguntas] que habia hallado entre los papeles de Juan de Torres Rocha, Maestro de Cappilla que habia sido 
de d[ic]ha Santa Yglessia cuia grande Çiençia en la Mussica era notoria, contenia las preguntas, que podian y debian haçerse a los oppossitores, que el Cauildo se siruiesse mandarla leer y que segun ella y por ella fuessen examinados : Y habiendomela entregado a mi el Secretario, la lei por mandado de el Cau ${ }^{\text {do }}$ de Verbo ad Verbum. Y leida, mando el Cauildo, que se pussiesse a continuaçion de este acto capitular, original con fee de mi el secret $^{\circ}$ de serla entregada, y por el orden de ella se les fuessen haçiendo las preguntas a $\mathrm{d}[\mathrm{ic}]$ hos oppossitores, y estos fuessen ejecutando lo Contenido en sus clausulas : y que para ello, yo el secretario las fuesse leyendo por partes una a una, y los oppossitores las ejecutassen, y en su cumplimiento, se fue ejecutando en la forma siguiente---------

Entro primero $\mathrm{D}^{\mathrm{n}}$ Mathias Pocurult [sic] Raçionero Ogranista de la Santa Yglesia de Ciudad Rodrigo, como mas moderno oppositor por no ser de orden sacro, y yo el secretario por mandado de el Cauildo, fui leyendo por su Orden y con separaçion las dos primeras clausulas de la memoria y preguntas que deçian assi=

[1] Primeramente, contrapuntos sobre Bajos en canto llano a compasillo, compas mayor, seisquialtera, ternario mayor. y menor, semibreues al Alçar, y minimas semicopadas $[i \underline{\text { Docu- }}$ mentos Ejercicios $n^{\circ} 1$ y $1^{\prime}$ ?]

Los mismos Contrapuntos sobre tiple en Cantollano-

Y el d[ic]ho $\mathrm{D}^{\mathrm{n}}$ Matheo Pocurull [sic], con assistencia del d[ic]ho $s^{r}$ M[aest]ro de Capilla, (sin embargo de su escussa) y de los $\mathrm{s}^{\text {res }}$ Raçioneros Musicos Y otros indiuiduos de la Capilla hechando el Bajo un ministril de Bajon, y el tiple, un moço de choro, cada uno en acto separado, hiço sus ejerçiçios al façistol, en un libro de canto llano, que abrio un moço de choro por la parte que le pareçio: y hechos se quedo dentro de la sala Capitular por haberse dicho no importaba viesse haçer sus ejerçiçios sobre el mismo a su cooppossitor-

E luego incontinenti por mandado de el Cauildo fue llamado, y entro en el, el d[ic]ho $\mathrm{D}^{\mathrm{n}}$ Pedro de San Martin y La Calle Organista de la Santa Yglesia de Astorga: y hiço los mismo ejerçiçios y se bolbio a salir afuera:

Y para prosseguir $\mathrm{d}[\mathrm{ic}] \mathrm{hos}$ ejerçiçios mando el Cauildo que yo el secretario leyesse otra clausula de el memorial de Preguntas, la qual lei y su tenor es el siguiente= -------

[4] Mas se les da un Bajo para que ponen las voces con la pluma [Véase Documentos Ejercicios $n^{\circ} 1$ y 1'].

Y habiendo entrado ambos oppossitores a un tiempo por mandado de el Cauildo y dadoseles d[ic]ho Bajo, lo ejecutaron con la pluma, y cada uno firmo su papel, habiendo hecho la compossiçion de repente alli luego en pressençia de el Cauildo, sobre la messa de la secretaria, sentado en el Banco, donde estaba yo el secretario, cada uno a su lado: Y assi ejecutados ambos papeles, los cantaron los $\mathrm{s}^{\mathrm{res}} \mathrm{R}^{\mathrm{os}}$ Mussicos de d[ic]ha Santa Yglesia, començando por el del oppossitor mas moderno: y despues de cantados mando el Cauildo se me entregassen a mi el secretario, para que los pussiesse con estos actos capitulares, sin manifestarlos a nadie, hasta que se me mandasse: Y por aora se quedo con este estado, para prosseguir a lo demas el sabado por la mañana, con lo qual se fenecio este Cauildo de que doy fee y lo firme.

Ante mi Joseph Martin de la fuente.

c [De otra mano:] Lo q[ue] se debe preguntar a los opositores q[ue] concurran a ser examinados de organista es lo siguiente $=$

[1] Primeramente contrapuntos sobre bajo en Cantollano, a compasillo, Compas maior, seisquialtera, ternario maior y menor, semibrebes al Alçar y Minimas semicopadas [sic]=

[2] Los mismos Contrapuntos se les pide sobre tiple en Cantollano $=$

[3] Mas sobre ocho, y diez puntos de dicho Cantollano hagan un Concierto a quatro con la pluma sobre bajo=

[4] Mas se les da un bajo para $\mathrm{q}[\mathrm{ue}]$ pongan las vozes con la pluma $=$

[5] Mas se les pide Contrapunto sobre Canto de organo, a compasillo, compas maior, seisquialtera, semibrebes al dar y al alzar, y minimas semicopadas $[$ sic $]=$

[6] Y tercera voz de contralto, y tiple echando un bajo, y luego de tenor y bajo echando otro bajo=

[7] Mas q[ue] toque el tiple y el Contralto y eche la terzera voz con el organo=

[8] Mas se les a de dar un passo a compasillo q[ue] entre las vozes a quatro, en q[ue] se ha de atender a la brebedad y limpieza de egecutarle, $\mathrm{y}$ otro a proporcionçilla con las mismas circunstancias y rigor=

[9] Mas se les a de dar a una voz de Contralto un tiple, el qual le ha de cantar segun su cuerda, y el organista le ha de acompañar echando la voz fuera=

[10] Mas se canta un chirie [sic] punto bajo, ô alto para $\mathrm{q}$ [ue] toque sobre el imitandole, y se les debe preguntar q[ue] tono es para ber si saben los diapasones, y tienen el verdadero conozimento de ellos, y tambien toquen sobre aquellos intentos=

[11] Mas cantara la Capp ${ }^{a}$ un berso de Magnificat para q[ue] imite el organista los temas de el cumpliendo con el Cantollano del tono $=$

[12] Mas ha de acompañar un berso a una chirimia, y otro a un Cantor, y otro a un Bajon= to alto $=$

[13] Mas a de acompañar una tonada de octabo tono pun-

[14] Mas un quatro que sea ayroso, no solo le ha de acompañar sino q[ue] lo an de imitar despues=

[15] Mas un salmo q[ue] acompañe natrual y aczidental=

[16] Mas se les a de dar un paso para un partido de dos tiples, y el mismo u otro para un partido de dos bajos=

[17] Mas si se quisiere, entonará el sochantre un himno para $\mathrm{q}[\mathrm{ue}]$ sigan el metro, o el ayre=

[Sigue con la letra del secretario del cabildo :] Esta es La Memoria de Preguntas que en el cau ${ }^{\text {do }}$ de oy Juebes, doçe de nobiembre de mill seisçientos y noventa y nuebe, entrego el $\mathrm{s}^{\mathrm{r}}$ $\mathrm{R}^{\circ} \mathrm{D}^{\mathrm{n}}$ Pedro de Pineda, de que doy fee y lo firme=

Joseph Martin de la fuente 
d) A continuación vienen los ejercicios manuscritos de los opositores:

-Matheo Pocurull [a continuación del ejercicio viene:] Este es el papel ejecutado en el Cauildo de oy Juebes doce de nobiembre de mill y seisçientos y nobenta y nuebe años de que doy fee y lo firme= Joseph Martin de la Fuente [Ejercio 1]

- [Firma el ejercicio:] Pedro de Samartin La Calle [y viene lo siguiente:] Este es el papel ejecutado en el cau ${ }^{\mathrm{do}}$ de oy Juebes doçe de nobienbre de mill y sesiçientos y nobenta y nuebe : de que doy fee y lo firme- Joseph Martin de la Fuente [Ejercicio 1']

e) $\mathrm{Cau}^{\mathrm{do}}$ en que se prossiguieron los ejerçiçios de los oppositores

En el Cauildo extra Ordinario que se hiço en la Santa Yglesia de Salamanca Sabado por la mañaña catorze de nobiembre de mill sesçientos y nobenta y nuebe años, en que Presidio el $\mathrm{s}^{\mathrm{r}} \mathrm{D}^{\mathrm{r}} \mathrm{D}^{\mathrm{n}}$ enrrique escon y enrriquez Dean y $\mathrm{Can}^{\mathrm{o}} \mathrm{de} \mathrm{d}[\mathrm{ic}]$ ha Santa Yglesia y presentes muchos $\mathrm{s}^{\text {res }}$ Dignidades, Canonigos, Raçioneros enteros, y medios Raçioneros Juntos y Congregados en su sala Capitular como lo tienen de usso y costumbre, se prossiguio en los ejerçiçios por los oppositores a la Media Raçion de Organista de d[ic]ha Santa Yglesia, y se ejecutaron en la forma y manera siguiente $=$

Pidio el d[ic]ho $\mathrm{s}^{\mathrm{r}} \mathrm{R}^{\mathrm{o}} \mathrm{d}$. thomas de Miziezes Maestro de Cappilla se aduirtiesse al Pertiguero tubiesse cuidado de que estando un oppossitor dentro del Cauildo haçiendo sus ejerçiçios, estubiesse el otro retirado en parte donde no pudiesse oirlos= y el Cauildo lo mando assi, y se le aduirtio al d[ic]ho Pertiguero-

El s ${ }^{r}{ }^{\circ}$ Mussico D. Domingo Garcia, dijo que para descargo de su conçiençia pedia mandasse el Cauildo se le mostrasse la memoria de preguntas dada por el $\mathrm{s}^{\mathrm{r}} \mathrm{R}^{\circ} \mathrm{D}$. Pedro de Pineda para verla, y el Cauildo mando, que yo el secret ${ }^{\circ}$ se la manifestasse y habiendola visto, pidio que respecto de haberse dicho se habia hecho por una del Maestro Juan de Torres Rocha se trajesse al Cauido el orijinal y el Cau ${ }^{\text {do }}$ mando se trajesse, y di[ch]o $s^{r} R^{o}$ Pineda dijo era solo un borrador y que le habia roto : de cuia respuesta se dio motiuo a pressumir que el memorial de Preguntas le habia hecho di[ch]o s $\mathrm{s}^{\mathrm{r}}$ Maestro de Cappilla, y di[ch]o s ${ }^{\mathrm{r}}$ cassi lo confesso si bien añadio que aunque lo hubiesse hecho no habia en ello fraude alguno porque ninguno de los oppossitores sabia por donde se habian de abrir los Libros de Canto para haçer los ejerçiçios y que para quitar toda sospecha y la que pudiesse haber (por ser cuñado de di[ch]o $\mathrm{s}^{\mathrm{r}}$ Maestro de Cappilla $\mathrm{D}^{\mathrm{n}}$ Pedro de Samartin y la Calle oppossitor) entrasse $\mathrm{D}^{\mathrm{n}}$ Matheo Pocurull cooppossitor y abriese los libros por donde quissiesse y le pareçiesse: Y el Cauildo mando los abriesse di [ch]o $\mathrm{D}^{\mathrm{n}}$ Matheo que fue llamado y entro y los abrio, por donde le pareçio habiendo yo el secretario leydo por mandado de el Cauildo dos clausulas de di[ch]o memorial de preguntas que deçian assi=------

[Al margen: Pregunta] [1] Mas se les pide Contrapunto sobre canto de Organo, a compassillo, compas mayor, seisquialtera, semibreues al dar y al Alçar y Minimas semicopadas-----------

[6] [Al margen: Otra] mas tercera voz de contralto y tiple hechando un bajo, y luego de tenor y Bajo, hechando otro Bajo=---------
Y di [ch]o $\mathrm{D}^{\mathrm{n}}$ Matheo Pocurrull, con assitençia, de di[ch]o $\mathrm{s}^{\mathrm{r}}$ Maestro de Cappilla, y de los $\mathrm{s}^{\text {res }} \mathrm{R}^{\text {os }}$ Mussicos y de otros individuos de di[ch]a Cappilla hiço sus ejerçiçios en un libro de Canto de Organo al facistol segun el Orden de di[ch]as dos preguntas: y hecho, aunque se habia de salir de la sala capitular, se le dejo en ella, para que viesse a su cooppossitor haçer sus ejerçiçios=-

E incontinenti fue llamado y entro $\mathrm{D}^{\mathrm{n}}$ Pedro de Samartin y la Calle cooppositor y hiço los mismos ejerçiçios en la misma forma, y hechos se salieron fuera ambos oppossitores-----

Prossiguiosse la Memoria de Preguntas y lei yo el secretario la siguiente

[7] [Al margen: Pregunta] Mas se les pide que toquen el tiple y el contralto y hechen la tercera voz con el Organo---

Bolbio a entrar el di[ch]o D. Matheo Pocurull, (y habiendo se aduertido que $\mathrm{D}^{\mathrm{n}}$ Pedro de Samartin su cooppossitor estubiesse en parte distante donde no pudiesse oirle) hiço el di[ch]o D.Matheo Pocurull, sus ejerçiçios en un Realexo que se estaua prevenido, dentro de la sala capitular, tocando en di[ch]o Realexo lo pedido en la pregunta: y hecho el ejerçiçio aunque se habia de salir fuera, se quedo en di[ch]a sala, por haber d[ic]ho el $\mathrm{s}^{\mathrm{r}}$ Maestro de Cappilla no importaba se quedasse à ver a su coopossitor haçer su ejerçiçio=-----------

E luego fue llamado el di[ch]o $\mathrm{D}^{\mathrm{n}}$ Pedro de Samartin y la Calle, y entro, y en di[ch]o Realejo hiço los mismos ejerçiçios$\mathrm{y}$ hechos se quedaron ambos en la sala capitular para prosseguir en ellos--------

Y Prossiguiendo la Memoria de Preguntas, yo el secretario lei otra que decia assi-

[8] [Al margen: Pregunta] mas se les a de dar un passo à compassillo, que entre las voçes a quatro en que se ha de atender a la breuedad y linpieça de ejecutarle, y otro de proporçionilla con las mismas circunstançias y rigor [Véase Ejecicio $n^{\circ} 2$ y $2^{`}$ ] $=-$

y aunque tocaba al sr Maestro de Cappilla haçer los papeles, se escusso para quitar sospecha. Y se mando por el Cauildo que cada opositor le içiese el suyo y que el del uno lo ejecutasse el otro, al Realexo. Y en di[ch]os papeles pusiessen por escrito y señal, diçiendo, passo que pregunte.= passo a que respondi: $Y$ en esta forma los hiçieron y señalaron: Y luego cada uno, hiço sus ejerçiçios y ejecuto el papel de el otro en el realejo=y se salieron fuera $=$

Y para continuar en di[ch]os ejerçiçios, yo el secretario, lei otra partida de la memoria de Preguntas, que deçia assi----

[9] [Al margen: Pregunta] Mas se le ha de dar a una voz de contralto, un tiple, el qual le ha de Cantar segun su Cuerda, y el Organista le ha de acompañar hechando la voz fuera--

Y para la ejecuçion de di[ch]a Pregunta, el $\mathrm{s}^{\mathrm{r}} \mathrm{R}^{\circ} \mathrm{D}$. Domingo Garcia por mandado de el Cauildo, y por escussa del $\mathrm{s}^{\mathrm{r}}$ Maestro de Cappilla hiço un papel que canto un tiple: y habiendo sido llamado el di[ch]o Dn Matheo Pocurull, y entrado en el Cauildo, lo acompaño con el Realejo; y en su pressençia, habiendo sido llamado, y entrado el di[ch]o Dn Pedro de Samartin y La Calle, hiço lo mismo, y se bolbieron a salir fuera- 
Y yo el secretario prossegui leyendo la memoria de Preguntas, y lei otra que deçia assi---

[10] [Al margen: Pregunta] Mas se canta un Kyrie punto bajo, $\mathrm{O}$ alto, para que toque sobre el imitandole. Y se les debe preguntar que tono es para ver si saben los Diapasones, y tienen el verdadero conocimiento de ellos, y tambien toquen sobre aquellos intentos-

Y habiendo sido llamado el d[ic]ho $\mathrm{D}^{\mathrm{n}}$ Matheo de Pocurull, entro en el Cauildo y acompaño con el Realejo, el Kyrie, al tiempo que lo iba cantando la Cappilla: y despues hiço ejerçiçio tocando solo, imitando el intento: y se quedo en la sala capitular: y se llamo al d[ic]ho Pedro de Samartin y La Calle, y entro, y hiço los mismos ejerçiçios, y se salieron de la sala capitular---

[15] Assi mando el Cauildo que los d[ic]hos oppossitores acompañassen con el Realejo, a algun Villançico, y habiendose conferido, se trajessen papeles de donde no pudiesse haber sospecha los hubiessen visto los opposittores, el di[ch]o s $\mathrm{R}^{\circ} \mathrm{D}$. domingo Garçia dijo daria uno y bueno, y que en su conçiençia asseguraba no tener los di[ch]os oppossitores notiçia alguna de el : Y habiendo el Cauildo mandado que d[ic] $\mathrm{ho}^{\mathrm{r}} \mathrm{R}^{\circ} \mathrm{D}$. Domingo Garçia lo diesse repartio sus papeles cuia Compossiçion era de a quatro, y habiendo sido llamado y entrado el di[ch]o Dn Matheo Pocurull le fue acompañando con el Realejo al tiempo que los $\mathrm{s}^{\text {res }} \mathrm{R}^{\text {os }} \mathrm{Mu}-$ sicos le iban cantando: y luego fue llamado y entro el di[ch]o $\mathrm{D}^{\mathrm{n}}$ Pedro de Samartin y la Calle, y hiço lo mismo: y hechos los d[ic] hos ejerçiçios se quedaron ambos en la sala capitular-

[16] Y para que los di[ch]os oppossitores hiçiessen mas demonstraçion de sus habilidades mando el Cauildo, que cada uno tocasse en el Realejo, lo que fuesse mas de su gusto: $Y$ cada uno lo hiço assi, tocando lo que fue mas de su ellecçion: y el Cauildo vistos los d[ic]hos ejerçiçios hechos dijo haberse hecho les bastantes [sic], para prueba de las habilidades de los oppossitores y mando cessassen, y dio por Cumplidos los ejerçiçios : dejandolo en este estado, con lo qual se feneçio el Cauildo, de que doy fee $\mathrm{y}$ lo firme $=$

Ante mi Joseph Martin de la fuente

[A continuación vienen los ejercicios de los 2 y 2 '; van seguidos de los textos siguientes: ] Paso que pregunte. Paso que respondi. Paso que Pregunte. Paso que respondi.

Este es el papel ejecutado en el Cauildo de oy Sabado catorce de Nobiembre de Mill seisçientos y Nobenta y nuebe de que doy fee y lo firme $=$ Joseph Martin de la fuente [no aparece el nombre o firma de Pocurull]

[En otra hoja viene lo siguiente :] Passos q[ue] Pregunte. Passos q[ue] respondi. Este es el papel ejecutado en el Cauildo de oy Sabado catorce de Nobiembre de Mill seisçientos y Nobenta y nuebe de que doy fee y lo firme= Joseph Martin de la fuente. Pedro de Samartin y la Calle [arriba, el nombre, y abajo, la firma, a la izquierda de la hoja]

[En otra hoja:] Este es el papel que el $\mathrm{s}^{\mathrm{r}} \mathrm{R}^{\circ}$ Mussico D. Domingo Garcia hiço en el Cauildo de oy Sabado catorce de nobiembre de Mill seisçientos y Nobenta y nuebe año: para que lo ejecutassen al Realejo los oppositores de que doy fee y lo firme $=$ Joseph Martin de la fuente. f) $\mathrm{Cau}^{\mathrm{do}}$ en que se señalo dia para La Prouission de la raçion de Organista

En el Cau ${ }^{\mathrm{do}} \mathrm{Ordin}^{\circ}$ que se hiço en la Santa Yglesia de Salamanca lunes diez y seis de Nobiembre de Mill Y Seiçientos y nobenta y nuebe años en que Presidio el $\mathrm{s}^{\mathrm{r}} \mathrm{D}^{\mathrm{r}} \mathrm{D}^{\mathrm{n}}$ enrrique escon y enrriquez Dean y Canonigo de d[ic]ha Santa Yglesia y presentes muchos ses Dignidades, Canonigos, Raçioneros enteros, y Medios Raçioneros, el d[ic]ho s ${ }^{\mathrm{r}}$ Dean Dijo y propusso como al Cauildo le era notorio que $\mathrm{D}^{\mathrm{n}}$ Pedro de Samartin y La Calle y $\mathrm{D}^{\mathrm{n}}$ Matheo Pocurull oppossitores a la Media Raçion de Organo de d[ic]ha Santa Yglesia Vacante por muerte de $\mathrm{D}^{\mathrm{n}}$ Fran $^{\mathrm{co}}$ Sanz de tejada su ultimo possehedor tenían hechos sus ejerçiçios y se les haçia mala obra en detenerlos en esta çiudad por la falta que haçian a sus yglesias y que assi viesse el Cauildo si gustaba de proeveher luego la d[ic]ha Media Raçion de Organista, o señalar otro dia para ello: y a caussa de haberse mouido session, sobre si se esperaban otros oppossitores, no habiendo benido en los terminos de los edictos, y sobre el modo que se habia obseruado en otras provissiones se me mando a mi el secretario leyesse lo actuado en la prouission de la d[ic]ha Media Raçion de Organista en el año de mill siesçientos y veinte y dos y habiendolo leydo acordo el Cauildo que mañana martes diez y siete de este mes se señalaba por dia para la prouission de d[ic]ha Media raçion de Organista en Cauildo Extra Ordinario y que en el los d[ic]hos oppossitores entrassen personalmente á informar de su justiçia: Con lo qual se fenecio este Cauildo: a que doy fee y lo firme=

Ante mi Joseph Martin de la fuente

g) $\mathrm{Cau}^{\mathrm{do}}$ en que se proueyo la Media Raçion de Organista [1] En el $\mathrm{Cau}^{\mathrm{do}}$ Extra Ordinario, que se hiço en la Santa Yglesia de Salam ${ }^{\text {ca }}$ Martes diez y siete de Nobiembre de Mill Seisçientos y Nobenta y nuebe años, en que Presidio el $\mathrm{s}^{\mathrm{r}} \mathrm{D}^{\mathrm{r}} \mathrm{D}^{\mathrm{n}}$ enrrique escon y Enrriquez Dean y Canonico de ella, estando Juntos y Congregados en su sala capitular como lo tienen de usso y costumbre, en conformidad con lo acordado en el Cauido antecedente, y por estar señalado el dia de oy para la prouission de la Media Raçion de eran

[2] Organista de d[ic]ha $S^{\text {ta }}$ yglesia Vacante por muerte de $\mathrm{D}^{\mathrm{n}} \mathrm{Fran}^{\mathrm{co}}$ Sanz de tejada su ultimo possehedor, mandaron que $\mathrm{D}^{\mathrm{n}}$ Pedro de Samartin y La Calle Organista de la s ${ }^{\text {ta }}$ Yglesia de Astorga, y D Matheo Pocurull Organista de la Santa Yglesiua de Çiudad Rodrigo, oppossitores a d[ic]ha Media Raçion de Organista, fuessen entrando por sus antiguedades en el Cuildo a informar de su Justicia, como con efecto entraron el primero el d[ic]ho $\mathrm{D}^{\mathrm{n}}$ Matheo Pocurull, y despues el d[ic]ho $\mathrm{D}^{\mathrm{n}}$ Pedro de Samartin y La Calle, y sentados cada uno durante su informe a mano diestra : de mi el secretario, en mi banco, que es el lugar que les señala el Cauildo, informaron y manifestaron testimonios y certificaçiones de las oppossiçiones que habian hecho en las Yglesias donde al presente Organistas y en otras, Y cada uno acabado su Ynforme se salio fuera $=\mathrm{Y}$ el Cauildo mando que algunos $\mathrm{s}^{\text {res }}$ Raçioneros titulares inteligentes en Mussica; (Como lo eran los $\mathrm{s}^{\text {res }} \mathrm{R}^{\text {os }} \mathrm{D}$. Diego Cantero de Vitoria, y D. Pedro de Pineda) y los $s^{\text {res }} R^{\text {os }}$ Mussicos, dijessen su sentir y pareçer çerca de la mas o menos habilidad, y meritos de los oppossitores, para que informado el 
$\mathrm{Cau}^{\mathrm{do}}$ procediesse a la Prouission, y en su Cumplimiento, fueron $\mathrm{d}[\mathrm{ic}]$ hos $\mathrm{s}^{\text {res }}$ informando en la forma siguiente--

El $\mathrm{s}^{\mathrm{r}} \mathrm{R}^{\circ} \mathrm{D}^{\mathrm{n}}$ Diego Cantero de Vitoria dijo no tenia cossa singular de que informan [sic]----------

El $s^{r} R^{\circ} D^{n}$ Pedro de Pineda: dijo que aunque tenia obligaçion a saber alguna cossa de Mussica para poder dar su parecer. Se remitia a lo que dijessen los $s^{\text {res }} R^{\text {os }}$ Mussicos----------

Los ${ }^{\text {res }} D^{n}$ Marcos Castañon y $D^{n}$ Santiago de Ribera, $R^{\text {os }}$ Cantores dijeron que ambos oppossitores eran benemeritos, $\mathrm{y}$ que el Cauildo podia haçer lo que fuere seruido------

[3] Los $\mathrm{s}^{\text {res }} \mathrm{D}^{\mathrm{n}}$ Franco Garcia, $\mathrm{D}^{\mathrm{n}}$ Domingo Garcia: $\mathrm{D}^{\mathrm{n}}$ Nicolas de Hasundoaga, $\mathrm{D}^{\mathrm{n}}$ Gaspar de Unsaluarte, y $\mathrm{D}^{\mathrm{n}}$ Miguel de Castellanos Montenegro, assimismo Raçioneros Cantores informaron, ser $\mathrm{D}^{\mathrm{n}}$ Pedro de Samartin y La Calle mas habil y Benemerito de la d[ic]ha Media Raçion de Organista que el d[ic] ho $\mathrm{D}^{\mathrm{n}}$ Matheo de Pocurrul por excederle a este Con Muchas bentajas en Çiençia, Manos y ydea que eran tres partes principales para el ministerio de el Organo, por Saber Como Sabia mas mussica, y ejecutar los tañidos al Organo Con mas primor y destreça y tener en ellos mejor gusto segun lo habían reconoçido en los ejerçiçios que uno y otro habian hecho assi en el Organo a las horas de el choro como en sus examenes, preguntas, y respuestas en la sala Capitular : y esta era su Sentir y pareçer--

[4] Y oidos los d[ic]hos informes y sin el del s $\mathrm{s}^{\mathrm{r}} \mathrm{R}^{\mathrm{o}} \mathrm{D}$. thomas de Miziezes Maestro de Cappilla que no assitio a este Cauildo por la dependençia de haber sido su Cuñado el d[ic]ho Dn Pedro de Samartin y La Calle oppossitor,)[i?] mando el Cauildo se proçediesse a la prouission de la d[ic]ha Media Raçion de Organista, Y para ello yo el Secretario fuesse dando y remitiendo Çedulas â todos los $\mathrm{s}^{\mathrm{res}}$ que estaban pressentes para que se votasse la $\mathrm{d}[\mathrm{ic}]$ ha prouission y elecçion, y yo el $\mathrm{d}[\mathrm{ic}]$ ho Secretario notario entregue â cada uno de los d[ic]hos $\mathrm{s}^{\text {res }}$ dos Çedulas en que iban escritos los nombres de los $\mathrm{d}[\mathrm{ic}] \mathrm{hos}$ dos oppossitores (y habiendo omitido, acaso por no haberse venido a la memoria, el haçer el juramento acostumbrado de votar por el que pareciere más benemerito al Serviçio de Dios y de la Yglesia) los d[ic]hos ses fueron votando con las d[ic]has Çedulas al Altar, en la Caja donde se Vota por Haba y altramuz, hechando las Cedulas en la Caja y Seno de el Haua, Y por que un sr Capitular por error hecho su voto, en el Seno del Altramuz, se le bolbieron a dar por mandado de el Cauildo, otras dos çedulas con los nombres de ambos oppossitores, $\mathrm{Y}$ hecho la una en el d[ic]ho Seno de el Haua, y Contados primero por mi el Secretario todos los $\mathrm{s}^{\text {res }}$ Prebendados pressentes en este Cauildo, que fueron quarenta y tres, llebe las d[ic]has Cajas al Cuerpo de el Cauildo y puestas sobre la messilla, que para tales cassos se pone delante del s ${ }^{\mathrm{r}}$ Dean, abri con su llaue el Seno de el Haua, y saque las Çedulas que estaban dentro, que fueron quarenta y tres $\mathrm{d}[\mathrm{ic}]$ ho $\mathrm{s}^{\mathrm{r}}$ Dean las fue abriendo y Leyendo $\mathrm{Y}$ regulados los Votos, pareçio haber tenido el d[ic]ho Dn Pedro de Samartin y La Calle veynte y nuebe Votos; y el d[ic]ho $\mathrm{D}^{\mathrm{n}}$ Matheo Pocurull catorce votos con que salio ellecto y nombrado Canonicamente y llebo la d[ic]ha Media Racion y Prebenda de Organista de d[ic] ha Santa Yglesia el d[ic]ho $\mathrm{D}^{\mathrm{n}}$ Pedro de Samartin y La Calle -----

Y luego incontinenti los d[ic]hos $\mathrm{s}^{\text {res }}$ Dean y Cavildo, mandaron a mi el presente notario secretario, saliesse a dar la nueba al d[ic]ho $\mathrm{D}^{\mathrm{n}}$ Pedro de Samartin y La Calle, y le llamase para que Viniesse al d[ic]ho Cavildo, y se le encomendasse la d[ic]ha media Racion y Prebenda como se acostumbra: para cuio effecto se me entrego un papel firmado de $\mathrm{d}[\mathrm{ic}] \mathrm{ho}^{\mathrm{r}}$ Dean que decía asi----

[al margen :Papel] $\mathrm{D}^{\mathrm{n}}$ Pedro de Samartin y La Calle Nuestro $\mathrm{s}^{\mathrm{r}}$ ha sido seruido que salga ellecto en la Racion y Prebenda de Organista de esta Santa Yglesia, de gracias, â nuestro $\mathrm{s}^{\mathrm{r}}$

por ello, y venga â tomar la possession. Dada en Nuestro Cauildo a diez y siete días de el mes de Nobiembre de mill seisçientos y nobenta y nuebe años= el Dean de Salamanca----

Y habiendo salido yo el Secretario y llamado al d[ic]ho $\mathrm{D}^{\mathrm{n}}$ Pedro de Samartin y La Calle; y dadole la noticia y entregadole el $\mathrm{d}[\mathrm{ic}]$ ho papel, hecho en el d1ic]ho Cauildo, y dio las gracias a los $\mathrm{d}[\mathrm{ic}]$ hos $\mathrm{s}^{\text {res }}$ por la honra y merced, que le habian hecho: $\mathrm{y}$ habiendose incado de rodillas delante del $\mathrm{s}^{\mathrm{r}}$ Dean, $\mathrm{d}[\mathrm{ic}]$ ho $\mathrm{s}^{\mathrm{r}}$ por si y en nombre de el Cauildo le dio y emncomendo la d[1ic]ha media Racion y prebenda de Organista de la d[ic]ha Santa Yglesia ad nutum capituli, y en la forma de la Bulla de su erecçion por imposiçion de un Bonete que el d[ic]ho $\mathrm{s}^{\mathrm{r}}$ Dean le pusso sobre su Cabeça: habiendo entrado el d[ic]ho $\mathrm{D}^{\mathrm{n}}$ Pedro de Samartin y La Calle con loba y manteo y reciuida la $\mathrm{d}[\mathrm{ic}] \mathrm{ha}$ encomienda se salio fuera=

Y luego incontinenti, $d[i c]$ ho Dean dijo y propusso sera raçon que al $\mathrm{d}[\mathrm{ic}]$ ho $\mathrm{D}^{\mathrm{n}}$ Matheo Procorull se le diesse alguna cossa para ayuda de costa de los passos que habia dado en la benida a d[ic]ha oppossicion y que en el año de mill seiscientos veinte y dos se habian dado cien $\mathrm{R}^{\mathrm{s}}$ a cada uno de zinco oppositores, en mesa capitular y fabrica por mitad, y que respecto, por ser solo el sobred[ic] ho se le podian dar dosçientos $\mathrm{R}^{\mathrm{s}}$ en $\mathrm{Cau}^{\mathrm{do}} \mathrm{y}$ fabrica por mitad; y el Cauildo pareçiendole ser corta Cantidad, acordose le diesse al d[ic]ho $\mathrm{D}^{\mathrm{n}}$ Matheo Pocurull, un doblon de a ocho que vale dosçientos y quarenta $\mathrm{R}^{\mathrm{s}}$ librados por mitad en mesda capitular y fabrica de d[ic]ha Santa Yglesia: Con lo qual se feneçio est Cauildo de que doy fee y lo firme=

Dile sus libranças

Antte mi

Juan Martin de la Fuente

h) Tassa de las costas de este processo fecha en contaduria de d[ic]ha Santa Yglesia de Salamanca, a 18 de Nobiembre de 1699 en la forma y manera siguiente----

-de quatro manos de papel para edictos y cartas--- $006 \mathrm{R}^{\mathrm{s}}$ -de la Ympression, quarenta $\mathrm{R}^{\mathrm{s}-----}$ 040R

-De treinta y seis edictos, los treinta y quatro para las $S^{\text {tas }}$ yglesias de afuera: y los dos para la d[ic]ha Santa Yglesia de esta $\mathrm{ciu}^{\mathrm{d}}$ y Universidad de ella, y de las certificaçiones de veinte y nueve de ellas que vinieron, digo de todas las $\mathrm{S}^{\text {tas }}$ yglesias, a quatro $\mathrm{R}^{\mathrm{s}}$ cada una: ciento y quarenta y quatro $\mathrm{R}^{\mathrm{s}}$------ $\quad 144 \mathrm{R}^{\mathrm{s}}$ $016 R^{s}$

De los portes de treinta y dos cartas, diez y seisR s $^{-}-$

De los autos del Proçesso, cedulas para votar y de todo lo demas, segun otras provisiones, parece se reduce su tassa, â ciento y treinta y dos $\mathrm{R}^{\mathrm{s}}$--------- $132 \mathrm{R}^{\mathrm{s}}$

Monta todo trescientos y treinta y ocho $\mathrm{R}^{\mathrm{s}}$ de vellon que se me libraron por quentta de lo que a su tiempo, hubiese de ganar el Prouis[or?] a su tiempo, y lo rubricaron los $\mathrm{s}^{\text {res }}$ contadores $=$ $338 \mathrm{R}^{\mathrm{s}}$ [Siguen tres rúbricas ilegibles. 
III-EJERCICIOS DE 1699

\section{Ejercicio 1}

$\mathbf{o}=\mathbf{o}$

[a]

Matheo Pocorull
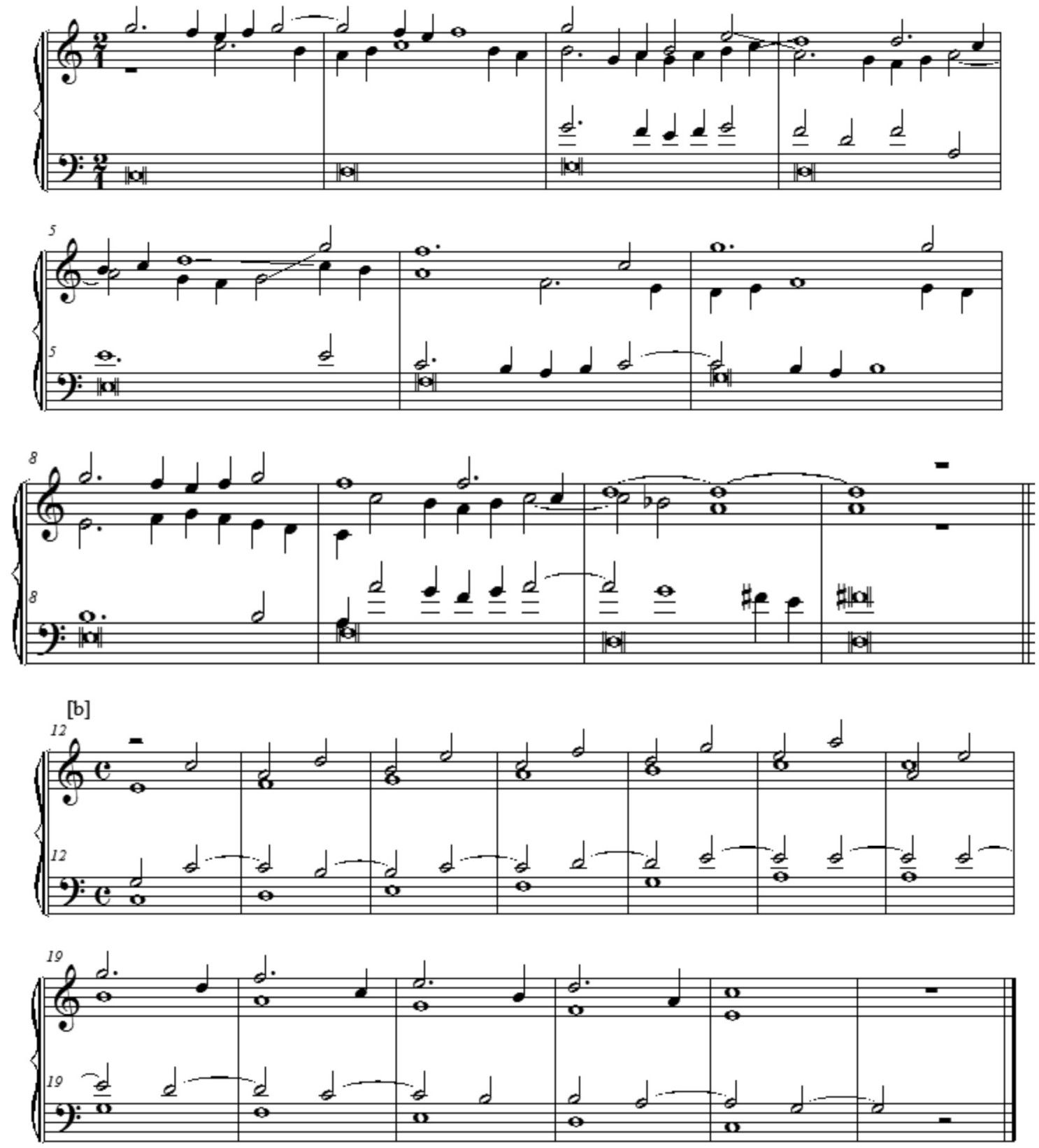

Este es el papel ejecutado en el Cauildo de oy Juebes doçe de nobiembre de mill y seisçientos y nobenta y nuebe dias de que doy fee y lo firme = Joseph Martin de laFuente 


\section{Ejercicio 1'}

$$
\mathbf{o}=\mathbf{o}
$$
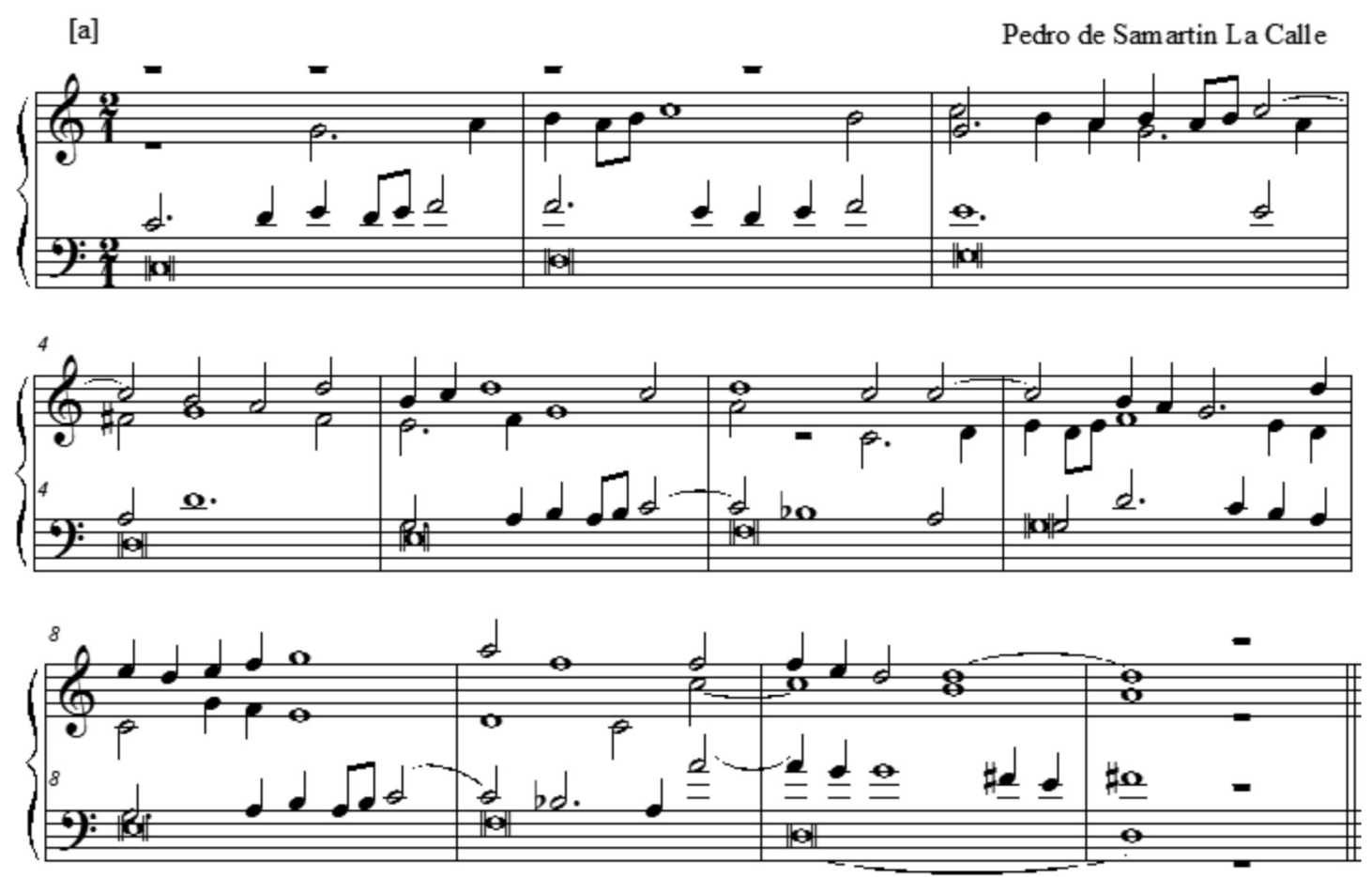

[b]

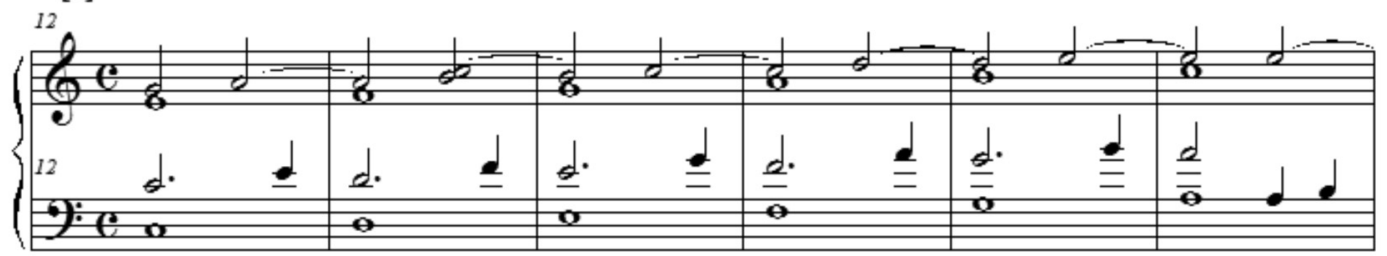

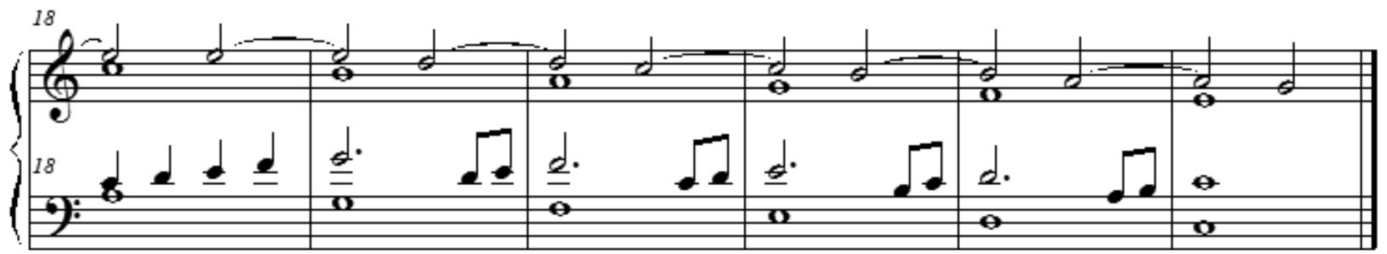

Este es el papel ejectuado en el Cauildo oy Juebes doçe de nobiembre de mill y seisçentos y noventa y nuebe : que doy fee y lo firme Joseph Martin de la Fuente [Firma:] Pedro de Samartin y La Calle 


\section{Ejercicio 2}

$\mathbf{o}=\mathbf{0}$

\section{Ejercicio 2a}

[Paso dado a Pocorull]

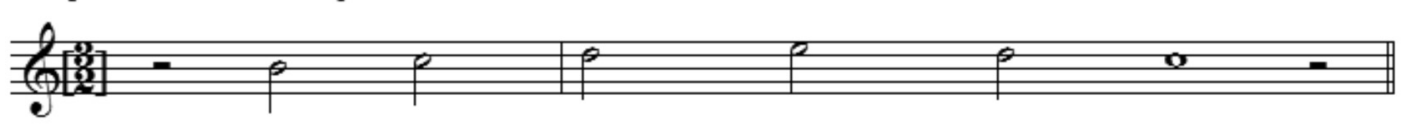

Ejercicio 2b

[Paso dado a Pocorull]

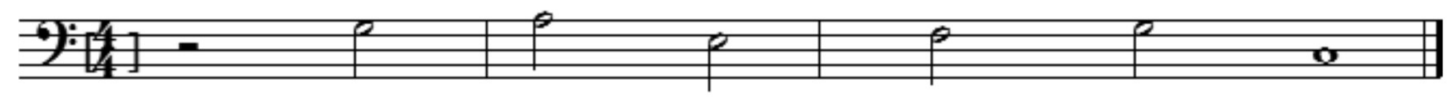

\section{Ejercicio 2c}

\section{[Paso dado a Samartin]}

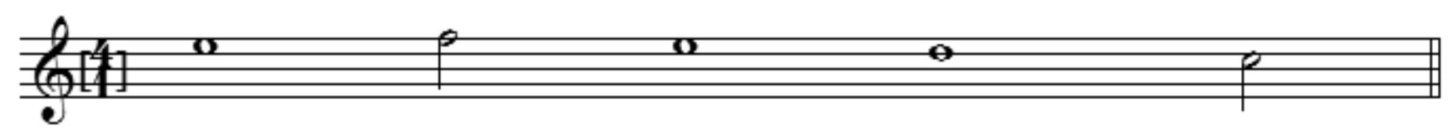

\section{Ejercicio 2d}

\section{[Paso dado a Samartin]}

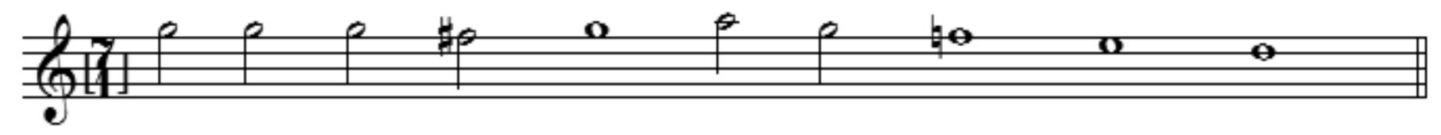




\section{Ejercicio 3}

$\mathbf{o}=\mathbf{0}$
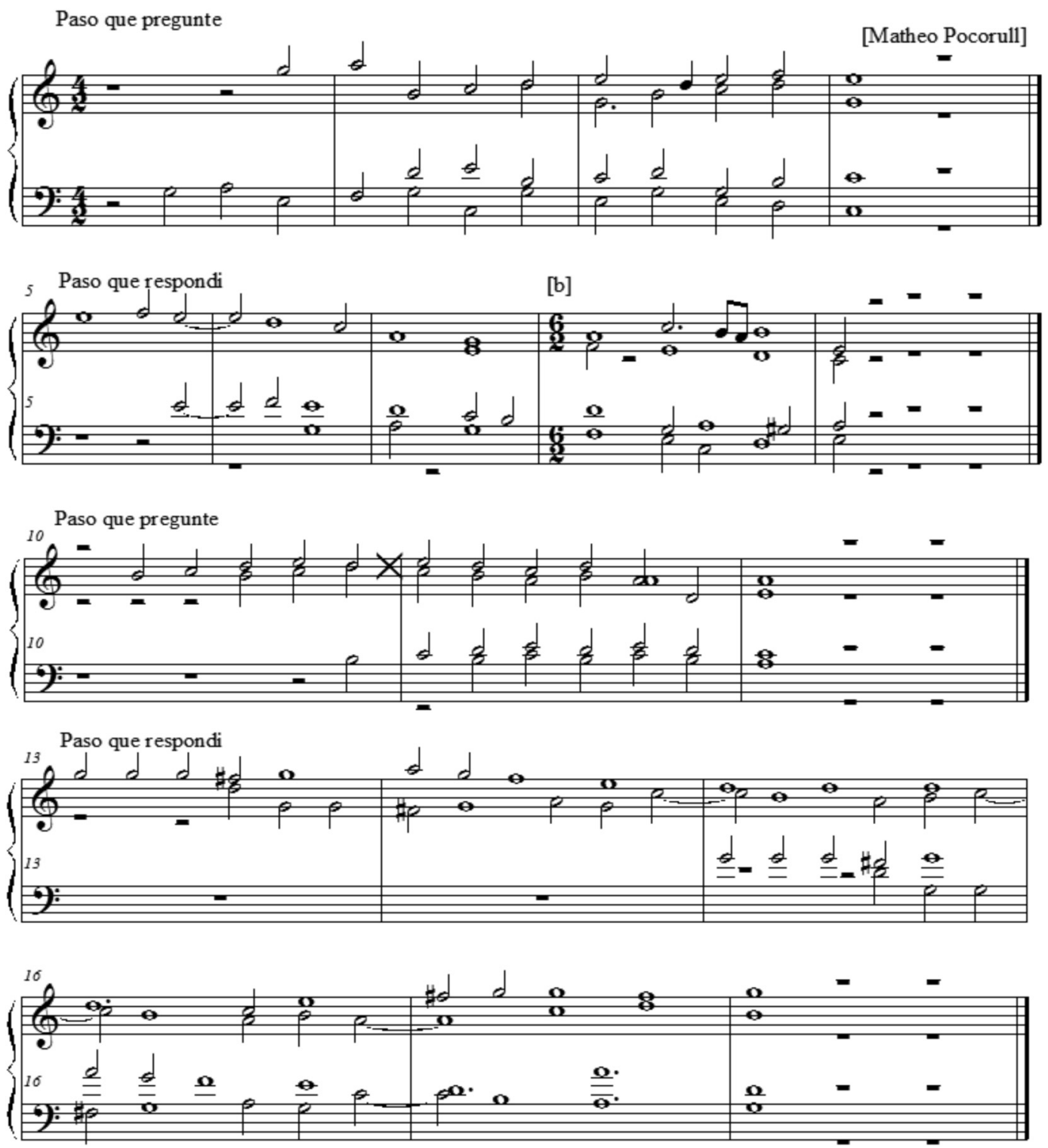

Este es el papel ejecutado el el Cauildo de oy Sabado catorçe de nobiembre de mille y seiçentos y noventa y nuebe de que doy fee y lo firme Joseph Marin de la Fuente 


\section{Ejercicio 3'}

$\mathbf{0}=\mathbf{0}$
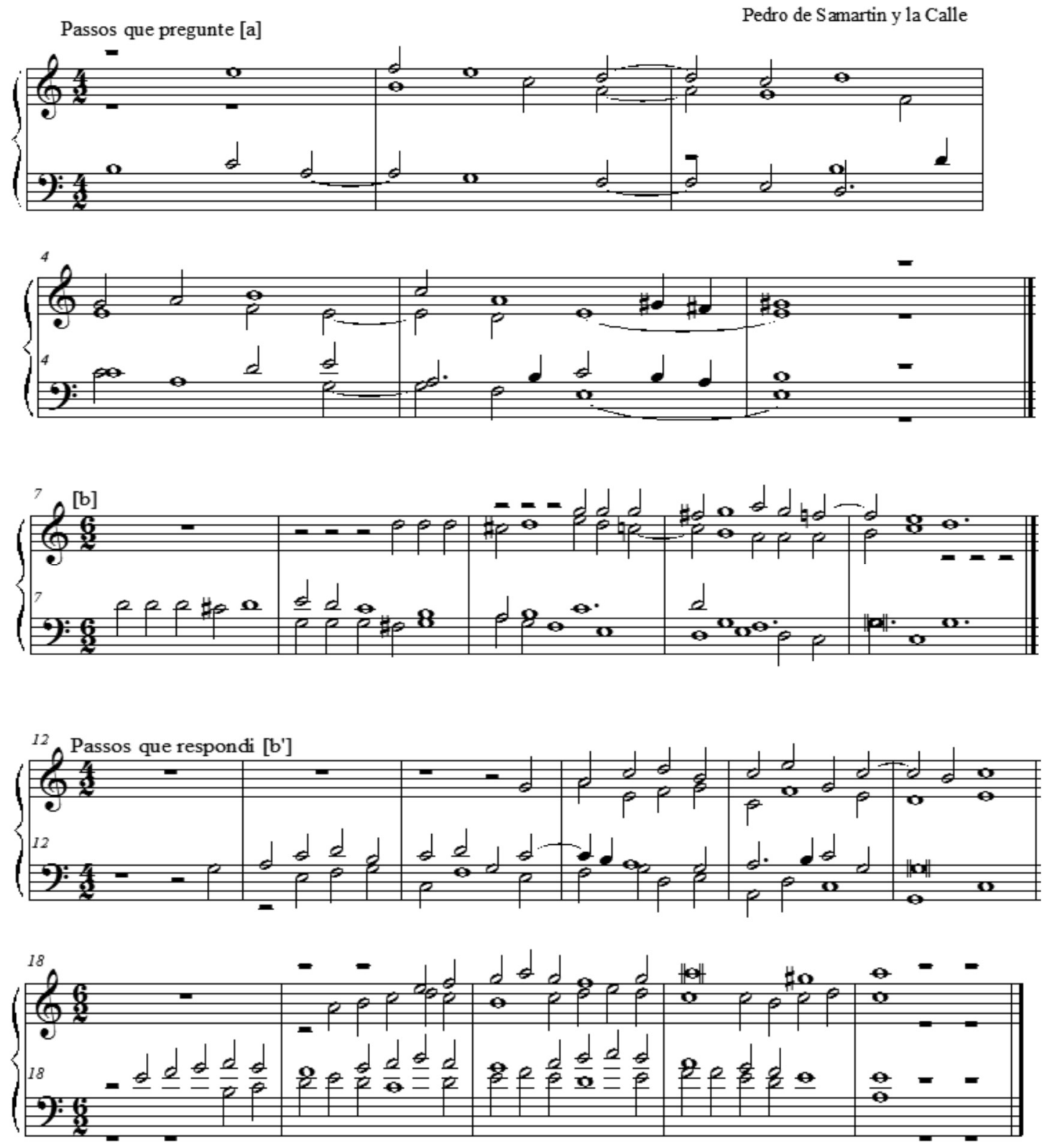

Este es el papel ejecutado en el cauildo de oy sabado catorçe de nobiembre de mill seisçientos y nobenta y nuebe de que doy fee lo firme. Josep Martin de la Fuente [Firma] Pedro de Samartin y la Calle 


\section{Ejercicio 4}

$\mathbf{o}=\mathbf{o}$

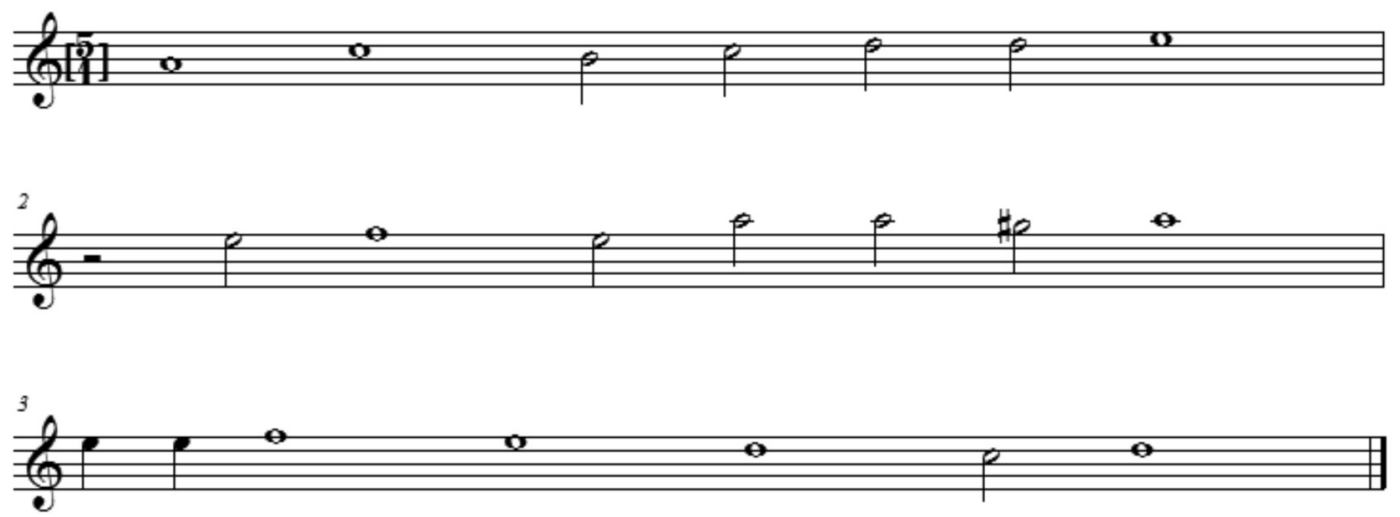

Este es el papel por el que el Sr. Ro. Mussico D. Domingo Garçia hiço en el Cauildo de oy sabado catorçe de nobiembre de mill seisçientos y nobenta y nuebe años para que lo ejecutasen al Realejo los oppositores de que doy fee y lo firmo. [Firma:] Joseph Martin de la Fuente

Recibido: 20.01.2018

Aceptado: 04.04.2018 